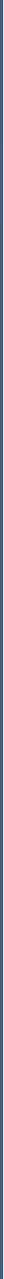

\title{
Stikstofwerking van organische meststoffen en hun relatie met gebruiksnormen
}





\section{Stikstofwerking van organische meststoffen en hun relatie met gebruiksnormen}

J.J. Schröder \& W. van Dijk

Dit onderzoek is in opdracht van het Ministerie van Landbouw, Natuur en Voedselkwaliteit uitgevoerd door de Stichting Wageningen Research (WR), business unit Agrosysteemkunde, als Additioneel Onderzoek in het kader van het $6^{\text {e }}$ Actieprogramma Nitraatrichtlijn (projectnummer 37104657 00).

WR is een onderdeel van Wageningen University \& Research, samenwerkingsverband tussen Wageningen University en de Stichting Wageningen Research.

Wageningen, juli 2019

Rapport WPR-916 
Schröder, J.J. \& W. van Dijk, 2019. Stikstofwerking van organische meststoffen en hun relatie met gebruiksnormen. Wageningen Research, Rapport WPR-916. 44 blz.; 3 fig.; 5 tab.; 40 ref.

Dit rapport is gratis te downloaden op https://doi.org/10.18174/477978

Uit organische mest komt niet alleen stikstof $(N)$ vrij in het jaar van toediening maar ook in de jaren daarna. Deze mineralisatie strekt zich in beginsel uit over tientallen jaren. Bij regelmatig gebruik van mest stijgt de N-werking ('NWC') in de loop van de jaren daarom naar een maximum. In de regelgeving hebben de voorgeschreven NWC's meestal betrekking op wat vrijkomt in het eerste jaar na toediening. Het jarenlange herhaalde gebruik van mest is aanleiding om in de advisering en regelgeving van de lange termijn NWC uit te gaan. Vanuit dat oogpunt kan de NWC van een aantal vloeibare organische mestsoorten verhoogd worden naar 70-80\% en die van vaste organische mestsoorten naar 55-75\%. Daarbij is wel aandacht nodig voor dubbeltellingen omdat de N-nawerking al impliciet in enkele bemestingsadviezen versleuteld is. Mocht de samenstelling van mest of de omstandigheden waaronder mest wordt toegediend veranderen, dan is met een relatief eenvoudig stelsel van rekenregels een redelijke schatting te maken van de NWC in het jaar van toediening en op lange termijn. Dat neemt niet weg dat nader experimenteel onderzoek zinvol is naar de mate van synchronisatie tussen mineralisatie en het $\mathrm{N}$-opnamepatroon van gewassen en naar de mate waarin organische mest tot extra emissie van elementaire $\mathrm{N}$ en lachgas leidt. NWC's spelen ook een rol in het gebruiksnormenstelsel. Er bestaat een verschil tussen de totstandkoming van N-gebruiksnormen van grasland en snijmaïs enerzijds en de overige akker- en tuinbouwgewassen anderzijds. De implicatie daarvan is dat een verhoging van de NWC bij grasland en snijmaïs vanuit een milieukundig oogpunt gepaard mag gaan met een navenante verhoging van de $\mathrm{N}$-gebruiksnormen maar die van de overige akker- en tuinbouwgewassen niet.

Trefwoorden: mest, N-werking, N-werkingscoëfficiënt, NWC, N-gebruiksnorm

(C) 2019 Wageningen, Stichting Wageningen Research, Wageningen Plant Research, Business unit Agrosysteemkunde, Postbus 16, 6700 AA Wageningen; T 03174807 00; www.wur.nl/plant-research

KvK: 09098104 te Arnhem

VAT NL no. 8113.83.696.B07

Stichting Wageningen Research. Alle rechten voorbehouden. Niets uit deze uitgave mag worden verveelvoudigd, opgeslagen in een geautomatiseerd gegevensbestand, of openbaar gemaakt, in enige vorm of op enige wijze, hetzij elektronisch, mechanisch, door fotokopieën, opnamen of enige andere manier zonder voorafgaande schriftelijke toestemming van Stichting Wageningen Research.

Stichting Wageningen Research is niet aansprakelijk voor eventuele schadelijke gevolgen die kunnen ontstaan bij gebruik van gegevens uit deze uitgave.

Rapport WPR-916

Foto omslag: mestinjecteur voor bouwland (Bron: Jan Huijsmans, Wageningen Research) 


\section{Inhoud}

$\begin{array}{ll}\text { Woord vooraf } & 5\end{array}$

$\begin{array}{ll}\text { Samenvatting } & 7\end{array}$

$\begin{array}{ll}\text { Summary } & 9\end{array}$

$\begin{array}{llr}1 & \text { Inleiding } & 11\end{array}$

$2 \quad$ Werkingscoëfficiënt $\quad 13$

$\begin{array}{llr}3 & \text { Bepalingsmethoden } & 17\end{array}$

$4 \quad$ Verschillende NWC's voor eenzelfde mest $\quad 19$

$\begin{array}{llr}5 & \text { Gebruiksnormenstelsel } & \mathbf{2 1}\end{array}$

$\begin{array}{llr}6 & \text { Onderbouwing gebruiksnormen } & 23\end{array}$

$\begin{array}{lll}6.1 & \text { Algemeen } & 23\end{array}$

6.2 Grasland en snijmaïs $\quad 23$

$\begin{array}{lll}6.3 & \text { Akker- en tuinbouwgewassen } & 25\end{array}$

$\begin{array}{llr}7 & \text { Compost en vaste mest } & 29\end{array}$

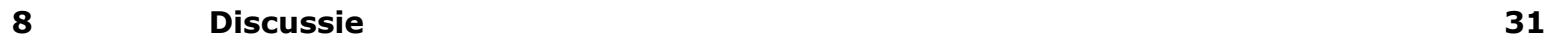

9 Aanbevelingen $\quad 35$

$\begin{array}{ll}\text { Literatuur } & \mathbf{3 7}\end{array}$

Bijlage 1 Protocol ter uniforme bepaling van de landbouwkundige $\mathbf{N}$-werking en het milieukundige lot van organische mest in het eerste jaar na toediening en op lange termijn

Bijlage 2 Verloop van wettelijke NWC's van varkensdrijfmest en enkele $\mathbf{N}$ gebruiksnormen 



\section{Woord vooraf}

Ook bij een qua tijdstip en plaatsing zo optimaal mogelijke toediening is uit organische mest meestal een kleiner deel van de toegediende stikstof $(\mathrm{N})$ beschikbaar voor het gewas dan uit kunstmest. De zogenaamde $\mathrm{N}$-werkingscoëfficiënt (NWC) van organische mest is daarom kleiner dan $100 \%$. In het kader van het gebruiksnormenstelsel heeft de overheid NWC's vastgesteld voor diverse soorten organische mest. De redeneringen achter de totstandkoming van die NWC's zijn niet altijd gedocumenteerd en lijken ook niet consistent. Het Ministerie van Landbouw, Natuur en Voedselkwaliteit heeft Wageningen UR daarom gevraagd om de redeneringen te harmoniseren en na te gaan of eventuele aanpassingen gevolgen zouden moeten hebben voor de N-gebruiksnormen. De opdracht hiertoe vond plaats in het kader van het Additionele Onderzoek ingevolge het $6 \mathrm{e}$ Nederlandse Actieprogramma voor de EU Nitraatrichtlijn. Dit rapport doet verslag van het genoemde onderzoek naar NWC's. Wij bedanken Ben Verwijs voor zijn commentaar op een eerdere versie van dit rapport.

Jaap Schröder \& Wim van Dijk 


\section{Samenvatting}

Uit organische mest komt niet alleen stikstof $(N)$ vrij in het jaar van toediening maar ook in de jaren daarna. Deze mineralisatie strekt zich in beginsel uit over tientallen jaren. Bij regelmatig gebruik van mest stijgt de N-werking ('NWC') in de loop van de jaren daarom naar een maximum. In de regelgeving hebben de voorgeschreven NWC's meestal betrekking op wat vrijkomt in het eerste jaar na toediening. Gezien het jarenlange herhaalde gebruik van mest is aanleiding om in de advisering en regelgeving van de lange termijn NWC uit te gaan. Vanuit dat oogpunt kan de NWC van een aantal vloeibare organische mestsoorten verhoogd worden naar $70-80 \%$ en die van vaste organische mestsoorten naar 55-75\%. Daarbij is wel aandacht nodig voor dubbeltellingen omdat de $\mathrm{N}$-nawerking al impliciet in enkele bemestingsadviezen versleuteld is. Mocht de samenstelling van mest of de omstandigheden waaronder mest wordt toegediend veranderen, dan is met een relatief eenvoudig stelsel van rekenregels een redelijke schatting te maken van de NWC in het jaar van toediening en op lange termijn. Dat neemt niet weg dat nader experimenteel onderzoek zinvol is naar de mate van synchronisatie tussen mineralisatie en het $\mathrm{N}$-opnamepatroon van gewassen en naar de mate waarin organische mest tot extra emissie van elementaire $\mathrm{N}$ en lachgas leidt. NWC's spelen ook een rol in het gebruiksnormenstelsel. Er bestaat een verschil tussen de totstandkoming van N-gebruiksnormen van grasland en snijmaïs enerzijds en de overige akker- en tuinbouwgewassen anderzijds. De implicatie daarvan is dat een verhoging van de NWC bij grasland en snijmaïs vanuit een milieukundig oogpunt gepaard mag gaan met een navenante verhoging van de $\mathrm{N}$-gebruiksnormen maar die van de overige akker- en tuinbouwgewassen niet. 


\section{Summary}

Manures supply nitrogen $(\mathrm{N})$ to crops in the year of their application but also in later years. This mineralisation extends over several decades. Regular manuring therefore results in a gradual increase of the $\mathrm{N}$ fertilizer replacement values (NFRV) of manures. However, prescribed NFRV's in the present regulations refer to 'first year's' $\mathrm{N}$ supply in most cases. In view of the common regular applications of manures, it seems reasonable to consistently adopt long term NFRV's in recommendations and regulations. We hence propose to increase the NFRV of liquid manures, including slurries, to $70-80 \%$ and those of solid manures to 55-75\%. Attention is required for possible 'double counting' because residual $\mathrm{N}$-effects of manures have in some cases become confounded with current crop-related $\mathrm{N}$ recommendations.

If the composition of a manure or the conditions under which manures are applied would change, a simple set of rules allows to make an informed estimate of the NFRV. However, there still is a need for a better insight into the synchronisation between mineralisation and the seasonal $\mathrm{N}$ uptake pattern of crops. Besides, we need to know more precisely when and where manures stimulate the production of elementary $\mathrm{N}$ and nitrous oxide.

As far as policies and regulations are concerned, there are close relationships between legal NFRV's and the crop specific $\mathrm{N}$ application standards. The premises behind the definition of $\mathrm{N}$ application standards of grassland and silage maize differ from those of other crops. That implies that the proposed raise of NFRV's justifies a proportional raise of the $\mathrm{N}$ application standards for grassland and silage maize as that has no negative environmental consequences. For any other crop a change of NFRV's does not justify a moderation of the $\mathrm{N}$ application standards. 


\section{Inleiding}

In de Nederlandse landbouw vindt de bemesting van gewassen voor een groot deel plaats in de vorm van organische meststoffen. Het gaat daarbij vooral om dierlijke mest. Organische mest bevat, naast organische stof (zelf voor circa de helft bestaand uit koolstof $(C)$ ), allerlei plantenvoedingsstoffen. De belangrijkste zijn stikstof, fosfor en kalium. Kalium $(K)$ is volledig en snel na toediening voor opname door planten beschikbaar. Fosfor $(P)$ komt weliswaar geleidelijk beschikbaar maar wordt bij herhaald gebruik van mest, met uitzondering van toepassing op fixerende gronden, ook volledig beschikbaar geacht. Voor stikstof $(\mathrm{N})$ is de beschikbaarheid echter onvolledig omdat een deel na toediening verloren gaat of niet tijdig of onmiddellijk beschikbaar komt. Het gebruiksnormenstelsel houdt in twee opzichten rekening met die beperkte $\mathrm{N}$-werking. In de eerste plaats gebeurt dit door de toegekende niet-werkzaamheid medebepalend te laten zijn voor uitspoelingsrisico's en, bijgevolg, de begrenzing van giften. In de tweede plaats gebeurt dit door gebruikers van organische mest toe te staan alleen het landbouwkundig werkzame deel in mindering te brengen op de toegelaten totale gift aan werkzame $\mathrm{N}$ in de vorm van mest en kunstmest.

De toegekende werking verschilt per organische mestsoort. De totstandkoming van de toegekende werkingen volgens de Meststoffenwet is niet altijd uniform beredeneerd (Van Dijk et al., 2004, 2005; Schröder et al., 2008b; CDM, 2017). Dit rapport beoogt de onderliggende redeneringen te harmoniseren en na te gaan of en, zo ja, welke consequenties dat zou kunnen of behoren te hebben voor het gebruiksnormenstelsel. 


\section{Werkingscoëfficiënt}

De N-werking van organische mest wordt uitgedrukt in een zogenaamde N-werkingscoëfficiënt (NWC). Dit getal geeft aan welk percentage van de toegediende $\mathrm{N}$ net zo beschikbaar is voor gewassen als de $\mathrm{N}$ in industrieel vervaardigde kunstmest-N. De NWC is daarom een relatieve maat ten opzichte van de beschikbaarheid van N uit kunstmest. De beschikbaarheid van N uit kunstmest wordt daarbij op $100 \%$ gesteld. Die $100 \%$ moet overigens niet verstaan worden als zou kunstmest- $\mathrm{N}$ zonder enig verlies in zijn geheel door een gewas worden benut. Voor alle beschikbare $\mathrm{N}$, ongeacht of die $\mathrm{N}$ van kunstmest- $\mathrm{N}$ of van organische mest afkomstig is, geldt namelijk dat slechts een deel door gewassen wordt opgenomen en vervolgens in oogstbare delen wordt geïnvesteerd. De rest spoelt uit, spoelt af of vervluchtigt.

De NWC van organische mest is doorgaans kleiner dan $100 \%$. Dat komt allereerst omdat organische mest meer of minder ammonium-N bevat waarvan een deel, afhankelijk van onder meer de gebruikte toedieningsmethode, als ammoniak $\left(\mathrm{NH}_{3}\right)$ zal vervluchtigen. Bij emissiearme toedieningstechnieken varieert de ammoniakemissie tussen $2 \%$ bij bouwlandinjectie tot $74 \%$ bij toediening van vaste mest op grasland (bijvoorbeeld Huijsmans et al., 2016). Organische mest bevat ook gemakkelijk afbreekbare koolstof $(\mathrm{C})$. Deze $\mathrm{C}$ kan de bacteriële omzetting van $\mathrm{N}$-verbindingen in gasvormige elementaire $\mathrm{N}\left(\mathrm{N}_{2}\right)$ en lachgas $\left(\mathrm{N}_{2} \mathrm{O}\right)$ stimuleren (in gewone taal 'denitrificatie', hoewel hierbij meer processen betrokken kunnen zijn) (Zaman et al., 2012; Velthof \& Rietra, 2018). De kans op 'denitrificatie' is groter bij diep ingewerkte en/of onvergiste mest van met name éénmagigen (kippen, varkens) dan bij oppervlakkig toegediende en/of vergiste mest van met name herkauwers.

Aannemende dat de totale verliezen aan $\mathrm{N}_{2}$ en $\mathrm{N}_{2} \mathrm{O}$ tezamen, maximaal hooguit het tienvoudige van de gemeten $\mathrm{N}_{2} \mathrm{O}$ verliezen bedragen (Ciarlo et al., 2008; Senbayran et al., 2012), variëren deze totale extra 'denitrificatie' verliezen verbonden aan het gebruik van organische mest naar schatting van 0 tot hoogstens 15 procentpunten van de aangeboden hoeveelheid N-totaal (Christensen, 1985; Thomson, 1989; Paul \& Zebarth, 1997; Velthof et al., 1997; Ellis et al., 1998; Rochette et al., 2000; Velthof et al., 2003; Vallejo et al., 2004; Schils et al., 2008; McGeough et al., 2012; Cameron et al., 2013). Naast ammonium-N bevat organische mest ook meer of minder organisch gebonden $\mathrm{N}$. Om beschikbaar te zijn voor planten moet deze $\mathrm{N}$ eerst mineraliseren. De mineralisatie vindt deels in het groeiseizoen plaats maar ook deels daarbuiten in periodes waarin gewassen geen vraag naar $\mathrm{N}$ uitoefenen. Ontijdig gemineraliseerde $\mathrm{N}$ staat daardoor in versterkte mate bloot aan verliezen naar lucht en water. Veel bouwlandgewassen stoppen met het opnemen van $\mathrm{N}$ na einde juli tenzij ze gevolgd worden door een groenbemester of vanggewas. De opname van N bij grasland kan echter tot in oktober doorgaan en in een zachte herfst of winter nog wel langer. De ontijdigheid van de mineralisatie beloopt daarmee naar schatting 5-45\%, afhankelijk van de lengte van het groeiseizoen (Figuur 1). De NWC van organische mest is niet alleen kleiner dan $100 \%$ vanwege die gasvormige verliezen $\left(\mathrm{NH}_{3}, \mathrm{~N}_{2}, \mathrm{~N}_{2} \mathrm{O}\right)$ en de deels ontijdige mineralisatie, maar ook omdat NWC's experimenteel vrijwel altijd worden bepaald in éénjarige veldproeven. Daarbij blijft de $\mathrm{N}$-nawerking per definitie buiten beeld (e.g. Schröder et al., 2013b). Die N-nawerking bestaat uit mineralisatie van organisch gebonden $\mathrm{N}$ voor zover die mineralisatie niet al in het eerste groeiseizoen na toediening plaatsvond. Voordat alle organische $\mathrm{N}$ van een bepaalde mestgift volledig gemineraliseerd is, verstrijken in principe tientallen jaren. In die zin wordt de $\mathrm{N}$-nawerking uitgesmeerd over vele jaren met een geleidelijke uitdoving; grafisch doet dit denken aan een staart (Figuur 2A). Bij regelmatig gebruik van eenzelfde hoeveelheid mest zullen de staartjes $\mathrm{N}$-nawerking van eerder gegeven giften accumuleren en raakt de gemiddelde jaarlijkse aanvoer van organisch gebonden $\mathrm{N}$ in beginsel in evenwicht met die geaccumuleerde staartjes $\mathrm{N}$-nawerking (Figuur 2B). Het is voor het principe van dit gedrag niet van belang of mest ieder jaar of regelmatig met tussenpozen gebruikt wordt, al heeft de CDM (2017) dat ooit per vergissing gemeld. Hoewel in de praktijk vrijwel zonder uitzondering sprake is van herhaald gebruik, ligt het accent in de landbouwvoorlichting, ook internationaal, meestal op die aan experimenten ontleende eerstejaars NWC (Webb et al., 2013). Op zijn best wordt de lange termijn NWC in voetnoten vermeld. Deze usance is voor een groot deel ook in het gebruiksnormenstelsel terechtgekomen. Op het eerste gezicht kan het aantrekkelijk lijken om dat gebruiksnormenstelsel simpelweg aan te passen door alle wettelijk voorgeschreven 'eerstejaars NWC's' door 'lange termijn 
NWC's' te vervangen. Als gevolg daarvan zullen toegestane kunstmest- $\mathrm{N}$ aanvullingen worden beperkt, zal het $\mathrm{N}$-bodemoverschot daardoor kleiner worden en als gevolg daarvan ook de milieubelasting. Dat dit een te éénvoudige voorstelling van zaken kan zijn, wordt in hoofdstuk 6 uitgelegd.

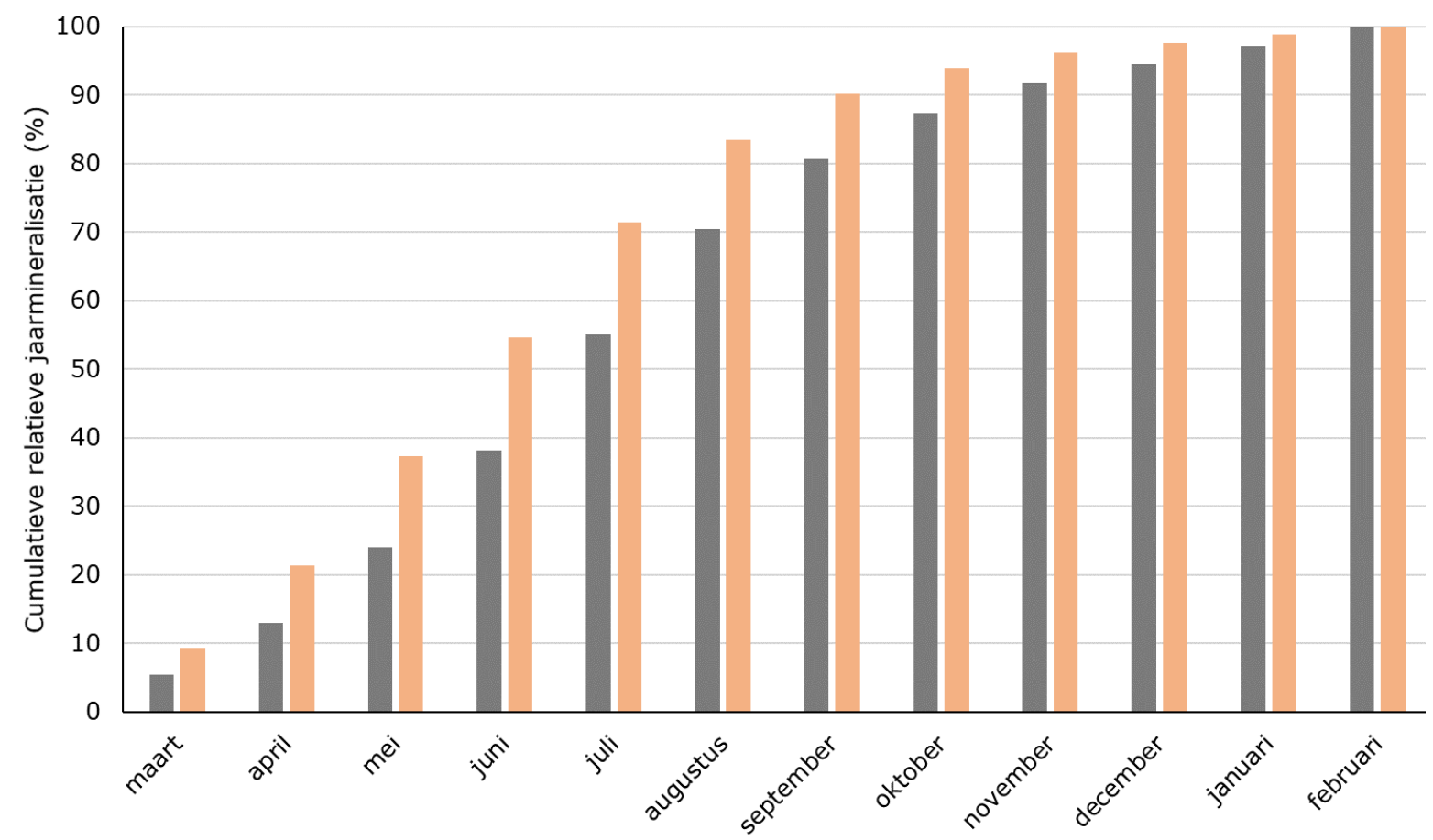

Maand tot waar de mineralisatie van maartgift gerekend wordt

-Rundvee $\backsim$ Varkens

Figuur 1. Gesimuleerde cumulatieve mineralisatie van organisch gebonden $N$ in rundvee- en varkensmest gedurende de 12 maanden na toediening op 1 maart, uitgedrukt als percentage van de mineralisatie die binnen een jaar plaatsvindt, onder gemiddelde Nederlandse weersomstandigheden (Schröder \& Van Middelkoop, 2016).

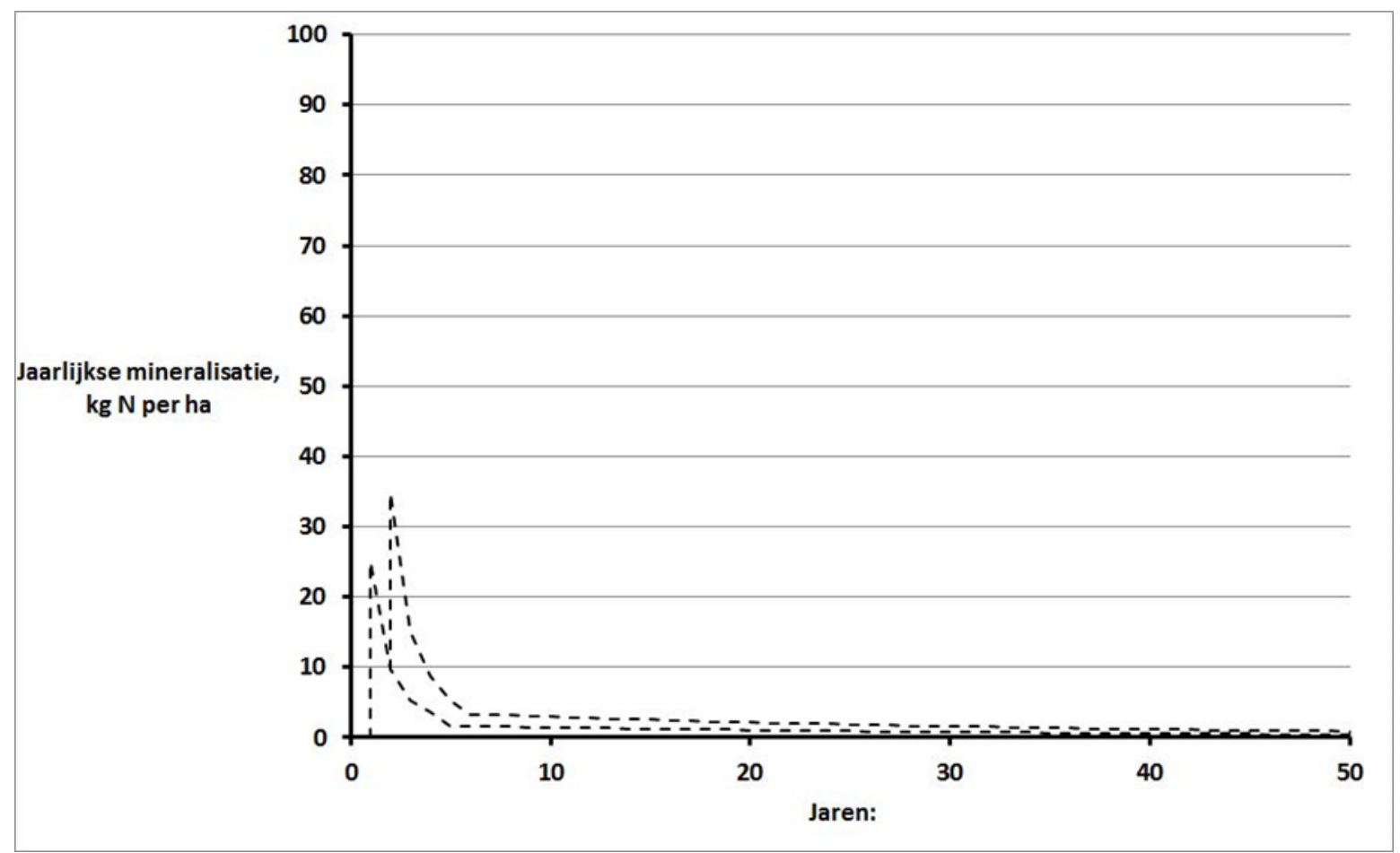

Figuur 2A. Gesimuleerde cumulatieve mineralisatie van $100 \mathrm{~kg}$ organisch gebonden mest- $\mathrm{N}$ per hectare na twee giften (naar: Schröder et al., 2013b). 


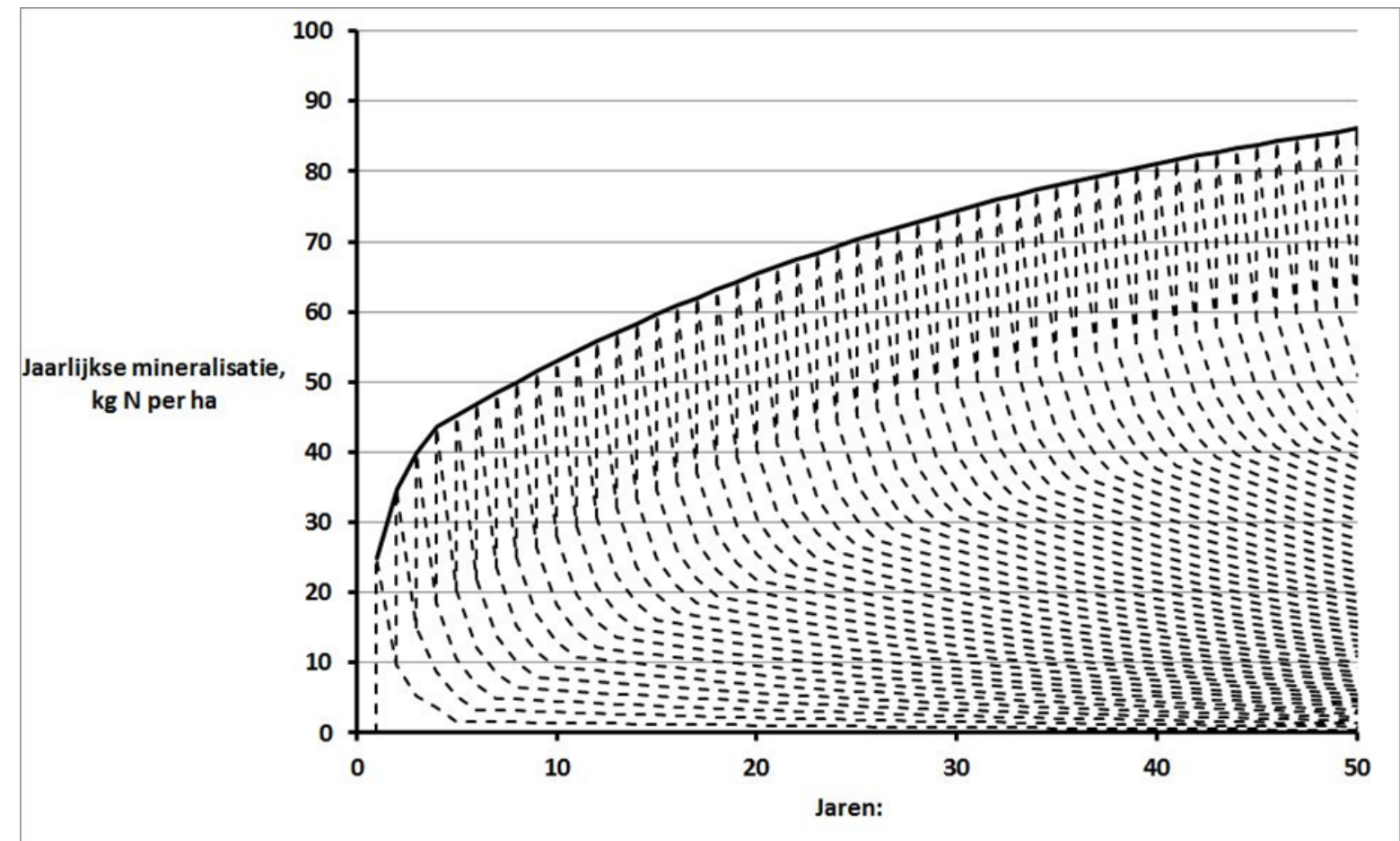

Figuur 2B. Gesimuleerde cumulatieve mineralisatie van $100 \mathrm{~kg}$ organisch gebonden mest- $\mathrm{N}$ per hectare na vele giften (naar: Schröder et al., 2013b). 


\section{Bepalingsmethoden}

NWC's zijn modelmatig en experimenteel vast te stellen. Modelmatig kan dat, bijvoorbeeld, door te schatten (wel bij voorkeur op basis van vele jaren experimenteel onderzoek) welke fracties van de ammonium- $\mathrm{N}$ en de organisch gebonden $\mathrm{N}$ in mest beschikbaar zijn voor een gewas. De beschikbaarheid van ammonium- $\mathrm{N}$ hangt af van het tijdstip en de wijze van toediening, eventuele verliezen als gevolg van extra 'denitrificatie', alsmede weersomstandigheden. De beschikbaarheid van organisch gebonden $\mathrm{N}$ houdt verband met de aard van die organische stof ('afbreekbaarheid'), al dan niet herhaald gebruik van mest, eventuele ontijdigheid van de mineralisatie in verband met de lengte van het groeiseizoen in combinatie met de heersende temperatuur. In Bijlage 1 wordt uitgewerkt hoe NWC's onder gemiddelde weersomstandigheden geschat kunnen worden op basis van een aantal karakteristieken. Op deze modelmatige schattingen wordt nog teruggekomen in een latere paragraaf. Experimenteel kan een NWC onder meer worden vastgesteld door de reactie van de gewasopbrengst op een organische mest te vergelijken met de reactie van datzelfde gewas op kunstmest-N. De NWC

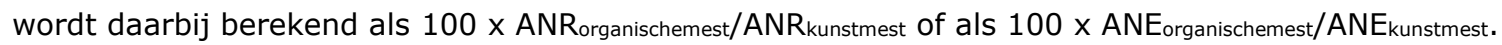
De ANR (apparent $N$ recovery) geeft weer welke fractie van de toegediende $\mathrm{N}$ als meeropbrengst in de vorm van $\mathrm{N}$ geoogst wordt. De ANE (apparent $\mathrm{N}$ efficiency) geeft weer welke fractie van de toegediende $\mathrm{N}$ als meeropbrengst in de vorm van (meestal) drogestofproductie geoogst wordt. De worden als volgt berekend: $A N R=(N$ opbrengst bemest $-\mathrm{N}$ opbrengstonbemest $) / \mathrm{Ngift}$ en ANE $=$ (opbrengst bemest $_{\text {- opbrengst }}$ onbemest $) / \mathrm{Ngift}$, waarbij de $\mathrm{Ngift}$ de hoeveelheid toegediende totaal $\mathrm{N}$ is. Hierbij moet wel bedacht worden dat de uitkomst sterk af kan hangen van 1) het type en de toedieningswijze van de kunstmest waarmee de organische mest vergeleken wordt, 2) de mate waarin het proefveld van voldoende andere voedingsstoffen dan $\mathrm{N}$ is voorzien, en 3 ) het aantal jaren gedurende welke de verschillende behandelingen reeds in de voorgaande jaren werden uitgevoerd. In Nederland worden organische mesten meestal vergeleken met de $\mathrm{N}$-kunstmest kalkammonsalpeter (KAS) die op een landbouwkundig gunstig moment wordt toegediend, te weten niet eerder dan vlak voor aanvang van het groeiseizoen en daarna zo nodig in de vorm van gedeelde giften. Als vergeleken zou worden met, bijvoorbeeld, ureum dan leidt dat meestal tot een hogere schijnbare NWC van organische mest omdat de ANR en ANE van veel ureum- $\mathrm{N}$ houdende meststoffen door de inherent hogere $\mathrm{NH}_{3}-\mathrm{N}$ verliezen lager zijn dan die van $\mathrm{KAS}$. Bij een suboptimale voorziening van het proefveld met andere voedingsstoffen dan N (waaronder P, K, calcium, magnesium, zwavel, micro-elementen) zal het gewas op een veldje dat organische mest ontvangt niet alleen positief op de gegeven $\mathrm{N}$ reageren, maar ook op de andere voedingsstoffen in die organische mest. Als gevolg daarvan zal de NWC overschat worden omdat het gemeten effect formeel geen $\mathrm{N}$-werking is maar een combinatie van de N-werking en de werking van andere voedingsstoffen (Schröder, 2005). Als een veldproef wordt aangelegd op een perceel dat voordien bemest werd, zullen in het eerste jaar na aanleg alle behandelingen, ook de onbemeste controle, profiteren van de $\mathrm{N}$-nawerking van voordien toegediende meststoffen. Bij voortzetting van de proef in een volgend jaar zal alleen de behandeling met organische mest profiteren van de extra N-nawerking van de organische mest die het jaar ervoor toegediend is. De berekende NWC zal als gevolg daarvan gaandeweg stijgen naarmate de proef over meer jaren wordt voortgezet (bijvoorbeeld Schröder et al., 2005a, 2005b, 2007a). 


\section{$4 \quad$ Verschillende NWC's voor eenzelfde mest}

Uit het voorgaande hoofdstuk blijkt dat er verschillende benaderingen en bronnen bestaan voor NWC's. Naast modelmatig berekende waarden in het eerste jaar na toediening en bij herhaald gebruik, zijn er de NWC-waarden die direct ontleend zijn aan experimenten. Idealiter komen de modelmatige berekeningen goed overeen met de experimenten omdat juist die experimenten tot (aanpassing van) de gebruikte modellen aanleiding gegeven zouden moeten hebben. Daarnaast bestaan er ook NWC's op basis van rekenregels in de bemestingsrichtlijnen van de LTO-Commissie Bemesting Grasland en Voedergewassen (CBGV) (www.bemestingsadvies.nl) en de LTO-Commissie Bemesting Akkerbouw- en Vollegrondsgroentegewassen (CBAV) (www.handboekbodemenbemesting.nl). Ook deze commissies varen op de uitkomsten van veelal dezelfde experimenten en de daarop gebaseerde modellen. Genoemde NWC's kunnen vergeleken worden met de NWC's die boeren volgens de Meststoffenwet (RVO, 2018) moeten hanteren bij het berekenen van de (resterende) kunstmest-N ruimte. Tabel 1 geeft de NWC's van die afzonderlijke bronnen. Die tabel bevestigt dat de wetgever voor de vloeibare organische mesten, waaronder ook de overwegend gebruikte drijfmesten, eerstejaars NWC's gekozen heeft, de beperkte eerstejaars $\mathrm{N}$-werking van weidemest verdisconteerd heeft in een verlaagde NWC van drijfmest op bedrijven die hun gras niet alleen maaien maar ook beweiden, en aan vaste mesten NWC's toekent die meest neigen naar de eerstejaars $\mathrm{N}$-werking tenzij toegediend op klei- of veengrond, toegediend in de winter en/of toegediend op een bedrijf dat het vee ook weidt. Ook de CBGV legt het accent op de eerstejaars NWC, wellicht omdat bij het vaststellen van de N-bemesting van grasland vooralsnog rekeningen gehouden wordt met het $\mathrm{N}$ leverende vermogen (NLV) van de bodem. Daarin zit de N-nawerking van, onder meer, organische mest besloten. De CBAV beperkt zich in de adviestabellen eveneens tot de eerstejaars NWC en wijst alleen in een voetnoot op de Nnawerking bij herhaald gebruik. De NWC's zoals aangegeven in de adviesbases van CBGV en CBAV zijn over het algemeen wat lager ingeschat dan de wettelijke NWC's. De modelmatig berekende NWC's gaan in Tabel 1 voor bouwland uit van emissie-arme toediening van mest op onbegroeid bouwland in het voorjaar waarbij de N-opname op 1 augustus stopt. Dat betekent dat NWC's lager zullen zijn dan vermeld bij, bijvoorbeeld, een minder emissie-arme toediening in een staand graangewas, temeer omdat de N-opname in dat geval een maand eerder stopt. De NWC is immers een uitdrukking van de mate waarin het desbetreffende gewas over de toegediende $\mathrm{N}$ kan beschikken: die beschikbaarheid is lager naarmate mest meer oppervlakkiger wordt uitgereden en naarmate de mineralisatie van de mest zich vanwege een relatief kortere groeiperiode sterker voorbij die groeiperiode afspeelt. Waar na de oogst van een gewas met zo'n relatief korte groeiperiode een tweede gewas of groenbemester volgt, kan deze volgteelt vanzelfsprekend alsnog profiteren van de $\mathrm{N}$-werking van de mest die aan het voorgaande gewas gegeven is. 
Tabel 1. Overzicht van de NWC's volgens verschillende bronnen, afgerond op 5-tallen.

\begin{tabular}{|c|c|c|c|c|c|c|c|c|c|c|}
\hline \multirow[t]{3}{*}{ Mestsoort } & & \multirow[t]{3}{*}{ Wettelijk (RVO, 2018) } & \multirow[t]{3}{*}{ CBGV } & \multirow[t]{3}{*}{ CBAV } & \multicolumn{2}{|c|}{ Model (Bijlage 1) } & & & \multicolumn{2}{|c|}{ Experimenten $\mathrm{f}$} \\
\hline & & & & & \multicolumn{2}{|c|}{ Grasland } & \multicolumn{2}{|c|}{ Bouwland } & \multirow[b]{2}{*}{ Eerste jaar } & \multirow[b]{2}{*}{ Lange termijn } \\
\hline & & & & & Eerste jaar & Lange termijn & Eerste jaar & Langere termijn & & \\
\hline \multirow[t]{5}{*}{ Vloeibaar } & Graasveedrijfmest & $45-60^{a}$ & $50-55$ & $40-55^{9}$ & 55 & 85 & 55 & 75 & $50-60$ & $(80)$ \\
\hline & Varkensdrijfmest & $60-80^{b}$ & & $50-75^{9}$ & & & 75 & 85 & $70-80$ & \\
\hline & Dunne fractie na scheiden, gier & 80 & & $45-90^{h}$ & $60-90^{h}$ & $85-90^{h}$ & $65-80^{h}$ & $80-90^{h}$ & $60-85$ & \\
\hline & Digestaat, graasvee & 60 & & $55-65$ & 60 & 85 & 70 & 80 & 65 & $(80)$ \\
\hline & Overig & 60 & & & & & & & & \\
\hline \multirow[t]{5}{*}{ Vast } & Graasvee & $30-60^{c}$ & 25 & $20-30$ & 25 & 80 & 25 & 55 & 30 & $(80)$ \\
\hline & Varkens, pluimvee, nerts & 55 & & $45-55$ & & & 55 & 75 & & \\
\hline & Compost & $10-25^{d}$ & & $5-15$ & & & 10 & 55 & 10 & \\
\hline & Dikke fractie & $30-50$ & & & & & $30-55^{h}$ & $55-70^{h}$ & & \\
\hline & Overig & $30-50^{e}$ & & & & & & & & \\
\hline Vloei/vast & Weidemest (feces, urine) & 0 & 0 & & 15 & $40-45$ & & & & \\
\hline
\end{tabular}

a laagste waarde voor bedrijven die ouder graasvee ( $>2$ jaar) weiden, hoogste waarde voor situatie zonder beweiding en niet op eigen bedrijf geproduceerde mest

b laagste waarde voor klei- en veengrond

c laagste waarde voor aangevoerde, niet op eigen bedrijf geproduceerde mest en voor mest toegediend tussen 1 september en 31 januari, ongeacht of aangevoerd dan wel op eigen bedrijf geproduceerd

d laagste waarde voor GFT, hoogste waarde voor champost

e afhankelijk van soort: zuiveringsslib, overige diersoorten, overige organische mest

f Geurink \& Van der Meer, 1995; Schils \& Kok, 2003, Schröder et al., 2005a, 2007a, 2008b, 2010, 2013 a.

9 laagste waarde geldt voor toediening met sleufkouter of zodenbemester in granen in voorjaar

$\mathrm{h}$ afhankelijk van scheidingsrendement en inwerktechniek

de in deze tabel getoonde cijfers beperken zich tot situaties waarin mest op bouwland emissiearm in het voorjaar op onbegroeid land wordt toegediend en de bouwlandgewassen tot 1 augustus $\mathrm{N}$ opnemen 


\section{$5 \quad$ Gebruiksnormenstelsel}

Het gebruiksnormenstelsel onderscheidt een norm voor het gebruik van $\mathrm{P}$ uit mest en kunstmest tezamen, een norm voor het gebruik van $\mathrm{N}$ in de vorm van (onbewerkte, bewerkte, verwerkte) dierlijke mest, en een norm voor werkzame $\mathrm{N}$ uit kunstmest en organische mest tezamen. De P-norm hangt af van het grondgebruik (wel/niet grasland) en de P-toestand van de bodem. De N-norm voor dierlijke mest hangt af van het bedrijfstype (niet/wel melkveehouderij waarbij melkveehouderijbedrijven desgewenst meer bemestingsruimte kunnen krijgen ('derogatie')) en de regio/grondsoort. De $\mathrm{N}$-norm voor werkzame $\mathrm{N}$ hangt af van het gewas, de oogstwijze (maaien of een combinatie van maaien en weiden) en de regio/grondsoort. Als op een perceel de P-norm, de $\mathrm{N}$-norm voor dierlijke mest en de N-norm voor werkzame N, respectievelijk 60 kg P $\mathrm{O}_{5}, 170 \mathrm{~kg} \mathrm{~N}$ en $200 \mathrm{~kg} \mathrm{~N}$ per hectare per jaar zou bedragen en de gebruikte dierlijke mest een $\mathrm{N} / \mathrm{P}_{2} \mathrm{O}_{5}$ verhouding van 3 zou hebben en een wettelijke NWC van $60 \%$, dan kan op dat perceel in principe maximaal $170 \mathrm{~kg}$ mest-N per hectare, $(170 / 3=) 57 \mathrm{~kg}$ mest $-\mathrm{P}_{2} \mathrm{O}_{5},(60-57=) 3 \mathrm{~kg}$ kunstmest $-\mathrm{P}_{2} \mathrm{O}_{5}$ per hectare, $(170 \times 0,60=) 102$ kg werkzame $\mathrm{N}$ uit mest per hectare, en nog (200-102=) $98 \mathrm{~kg}$ kunstmest-N per hectare worden toegediend. Als de NWC, bijvoorbeeld, $80 \%$ zou hebben bedragen, dan moest de gift van kunstmest- $\mathrm{N}$ tot $(200-(170 \times 0,80)=) 64 \mathrm{~kg}$ per hectare beperkt worden. Het voorgaande laat zien hoe de wettelijk toegekende NWC's effect hebben op de totale hoeveelheid aan te voeren N, waaronder kunstmest-N. Dat betekent dat beleidsmakers de milieubelasting kunnen verlagen zonder de $\mathrm{N}$-gebruiksnorm te hoeven veranderen. Een dergelijk besluit komt feitelijk overéén met een verlaging van de toegestane $\mathrm{N}$-gift. 


\section{Onderbouwing gebruiksnormen}

\subsection{Algemeen}

Op verzoek van het Ministerie van LNV heeft Wageningen University \& Research rond de eeuwwisseling een verkenning uitgevoerd naar bemestingsnormen die in overeenstemming zijn met milieukundige doelstellingen. Daartoe zijn afzonderlijke projecten uitgevoerd voor enerzijds grasland en snijmaïs, de dominante gewassen op melkveehouderijbedrijven, en anderzijds akker- en tuinbouwgewassen. Het ministerie heeft de vraagstellingen voor die projecten verschillend geformuleerd. Wageningen UR heeft de opdrachten wel in beide gevallen met eenzelfde model uitgevoerd (Schröder et al., 2007b, 2011; Van Dijk \& Schröder, 2007). Het gebruikte model neemt relaties aan tussen het aanbod van $\mathrm{N}$, het aanbod aan plant-beschikbare $\mathrm{N}$, de opname van plantbeschikbare $\mathrm{N}$ door gewassen en de uitspoelbaarheid van het verschil tussen de aangeboden $\mathrm{N}$ en de opgenomen $\mathrm{N}$. Het verschil tussen aangeboden $\mathrm{P}$ en opgenomen $\mathrm{P}$ ('P-overschot') wordt hieruit berekend op basis van $\mathrm{P} / \mathrm{N}$ verhoudingen in mest en gewas. Bij de berekening van de hoeveelheid werkzame $\mathrm{N}$ wordt aangenomen dat een deel van het $\mathrm{N}$-aanbod in de organische mest als gevolg van NH3-vervluchtiging en ontijdige mineralisatie niet beschikbaar is voor het gewas. Het model houdt geen rekening met eventuele extra 'denitrificatie' bij gebruik van organische mest. De aard van het $\mathrm{N}$ bodemoverschot wordt daarmee op het niveau van een bedrijf als geheel niet bepalend geacht voor de uitspoelbaarheid (Schröder et al., 2007b; Van Dijk \& Schröder, 2007). Deze aanname is te verdedigen zolang de voorspelbaarheid van 'denitrificatie' in relatie tot de aard van het N-bodemoverschot beperkt blijft vanwege tekortschietende kennis en zo lang het beleid en de daarvoor gebruikte modellen niet aangrijpen op perceelniveau maar op bedrijfsniveau of zelfs het niveau van regio's. Op het niveau van bedrijven en vooral regio's komen de diverse soorten $\mathrm{N}$-bodemoverschot en bijgevolg de plaatselijk hogere en lagere 'denitrificatie' alle in meer of mindere mate voor.

\subsection{Grasland en snijmaïs}

Voor grasland en snijmaïs luidde de vraag van het ministerie bij welke combinaties van rundveedrijfmest en kunstmest-N (KAS) de $\mathrm{N}$-opbrengst gemaximaliseerd wordt zonder dat daarbij sprake is van P-ophoping of P-uitmijning en zonder dat daarbij het grondwater onder zandgrond (hangwater onder lössgrond) meer dan $50 \mathrm{mg}$ nitraat (11,3 $\mathrm{mg} \mathrm{NO} 3-\mathrm{N}$ ) per liter bevat of het oppervlaktewater nabij klei- en veengrond meer dan 11,3 mg N-totaal per liter bevat. Bij die verkenning is een onderscheid gemaakt tussen grondsoorten, droogteklassen (binnen zandgronden), en oogstwijzen (maaien of combinatie van maaien en weiden). Als uitgangspunt is de lange termijn NWC van organische mest, in dit geval rundveedrijfmest, aangehouden. Bij de toenmalige berekeningen is die voor zowel grasland als bouwland gesteld op $78 \%$ (cf. gemodelleerde eerstejaars en langere termijn NWC van rundveedrijfmest van, respectievelijk, $55 \%$ en $80-85 \%$ volgens Tabel 1 , Bijlage 1). De verkenning heeft geresulteerd in rapporten met combinaties van rundveedrijfmest- $\mathrm{N}$ en kunstmest- $\mathrm{N}$, beide uitgedrukt in termen van hun $\mathrm{N}$-totaal inhoud, per afzonderlijke situatie (Schröder et al., 2005c, 2009). Die afzonderlijke situaties zijn overigens in latere fases door het ministerie geaggregeerd ('platgeslagen') in een beperkt aantal grotere groepen. Voor wat betreft de norm voor werkzame $\mathrm{N}$ werd uiteindelijk een onderscheid gemaakt tussen al dan niet weiden en tussen zand \& löss dan wel klei dan wel veen. Hierbij heeft het ministerie impliciet een bepaalde verdeling van de zandgronden over de diverse droogteklassen verondersteld. Voor wat betreft de norm voor mest- $\mathrm{N}$ werd uiteindelijk een onderscheid gemaakt tussen wel/geen toegekende derogatie en regio's. Dat laatste resulteerde in toegelaten mest- $\mathrm{N}$ giften op bedrijfsniveau (inclusief weidemest, te weten feces en urine) van hetzij 170, 230 of $250 \mathrm{~kg}$ mest-N per hectare per jaar. Aan die mestgiften is door het ministerie vervolgens een NWC toegekend van hetzij $60 \%$ voor bedrijven die hun grasland alleen maaien en $45 \%$ voor bedrijven die hun grasland behalve via maaien ook via beweiding oogsten. Beweiding door jongvee en hobby-dieren zijn overigens niet bepalend voor het antwoord op de vraag 
of geweid wordt of niet. Die NWC van $45 \%$ bij beweiding is ook van toepassing op het snijmaïsland op dat soort bedrijven aanwezig kan zijn. De som van de berekende kunstmest-N en de aldus werkzaam veronderstelde mest-N, vormde de uiteindelijk gekozen norm voor werkzame N ('de N-gebruiksnorm') bij elke specifieke situatie. Daarbij gold wel als extra bepaling dat de op die manier berekende $\mathrm{N}$ gebruiksnorm niet hoger mocht zijn dan wat de LTO-Commissie Bemesting Grasland en Voedergewassen (CBGV) op dat moment als landbouwkundig gewenst $\mathrm{N}$-advies hanteerde (www.bemestingsadvies.nl). Die aftopping heeft betrekking op klei- en veengronden omdat landbouwkundig optimale bemestingsadviezen daar, anders dan op zand- en lössgronden, niet onderschreden behoefden te worden om aan milieudoelstellingen te kunnen voldoen. De opgelegde NWC van $60 \%$ is op zichzelf een redelijke schatting van (de bovengrens van) de eerstejaarswerking van rundveedrijfmest zoals die in experimenten gevonden wordt. Uit experimenten volgt namelijk dat een NWC van gemiddeld 50-60\% haalbaar is zonder noemenswaardige verschillen tussen grasland en bouwland (Geurink \& Van der Meer, 1995; Schils \& Kok, 2003; Schröder et al., 2005a, 2007a, 2010, 2013a). De achtergrond van de door het ministerie toegekende NWC-waarde van $45 \%$ op weidende bedrijven is voor zover we hebben kunnen nagaan nergens op schrift onderbouwd. In de praktijk wordt aan weidemest (urine, feces) geen $\mathrm{N}$-werking toegekend vanwege de sterke concentratie van urine en feces op een relatief beperkte oppervlakte van een perceel. Uit literatuurgegevens blijkt echter dat weidemest wel degelijk een beperkte bemestende waarde heeft (CDM, 2017). Schröder et al. (2005c, 2007b, 2009) schatten de eerstejaars NWC van weidemest op 15\%. Tabel 2 laat zien wat de geschatte (volgens Bijlage 1) gemiddelde NWC is van alle mest, inclusief weidemest, in afhankelijkheid van de fractie weidemest binnen een totale mest- $\mathrm{N}$ productie van $250 \mathrm{~kg}$ mest- $\mathrm{N}$ per hectare bedrijfsoppervlakte per jaar, uitgaande van NWC's van $50 \%$ en $80 \%$ voor drijfmest in, respectievelijk, het eerste jaar en op lange termijn. Overeenkomstige waarden voor weidemest zijn $15 \%$ en $45 \%$. Daaruit blijkt dat een bedrijfsgemiddelde eerstejaars NWC van $45 \%$ op zichzelf een plausibele schatting is. Bij een weidemestproductie van 40-50 kg N per hectare per jaar (Van Bruggen, 2018) komt dat overeen met een gemiddelde lange termijn NWC op bedrijfsniveau van ruim 70\% (Tabel 2).

Tabel 2. Gewogen gemiddelde geschatte eerstejaars en lange termijn NWC van rundveedrijfmest in afhankelijkheid van graslandaandeel en weidemestproductie met als uitgangpunt een eerstejaars NWC van $50 \%$ voor drijfmest en $15 \%$ voor weidemest en lange termijn NWC van $80 \%$ voor drijfmest en $45 \%$ voor weidemest.

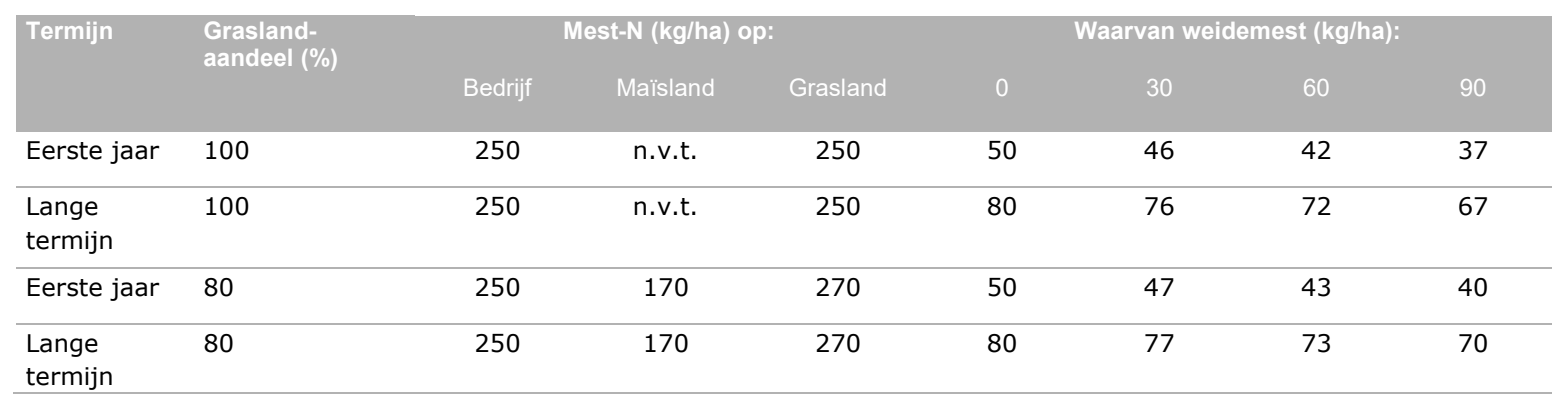

De vanuit Wageningen UR gerapporteerde milieukundig verantwoord geachte combinaties van mest en kunstmest rekenen bij grasland en snijmaïs, zoals aangegeven, met de lange termijn NWC van organische mest. Verhogingen van de wettelijk toegekende NWC-waarden zijn op zichzelf logisch omdat die hogere waarden passen bij het veeljarige gebruik van mest. Het zou echter niet terecht zijn om in dat geval niet gelijktijdig ook de N-gebruiksnormen te verhogen. Zonder zo'n aanpassing van de gebruiksnorm voor werkzame N zou zo'n verhoging van de wettelijke NWC de kunstmest-N giften slechts verlagen. Dat is onnodig vanuit het gezichtspunt van de beoogde $\mathrm{N}$-emissies naar het water (afgezien van andere overwegingen om $\mathrm{N}$-gebruiksnormen te herzien; zie discussie paragraaf), kost naar schatting 6-11\% aan $\mathrm{N}$-opbrengst en kan leiden tot een verminderde benutting van mest-P en, bijgevolg, een verhoogde ophoping van P tenzij de gebruiksnorm voor dierlijke mest verlaagd zou worden. Dit wordt zichtbaar gemaakt in Tabel 3. Uit diezelfde tabel blijkt overigens ook dat de simulaties aangeven dat: 
- $\quad$ op matig droge zandgrond met de huidige toegelaten mest- $\mathrm{N}$ en kunstmest- $\mathrm{N}$ giften vrijwel altijd aan nitraatconcentratiedoelstelling voldaan wordt.

- $\quad$ alleen maaien ondanks de hogere kunstmest- $\mathrm{N}$ gift meest tot een lichte daling van nitraatconcentraties leidt.

- $\quad$ eenzelfde $\mathrm{N}$-gebruiksnorm een hogere nitraatconcentratie geeft naarmate die norm meer met drijfmest en vooral weidemest wordt ingevuld.

\subsection{Akker- en tuinbouwgewassen}

Bij akker- en tuinbouwgewassen luidde de vraag van het ministerie met welk percentage de in 2006 geldende normen voor werkzame $\mathrm{N}$ ('de N-gebruiksnormen') van uitspoelingsgevoelige gewassen gekort zouden moeten worden om op zand- lössgronden aan een bepaalde waterkwaliteitsnorm te voldoen. Uitspoelingsgevoelige gewassen werden daarbij gedefinieerd als gewassen die bij bemesting met kunstmest- $\mathrm{N}$ volgens advies een $\mathrm{N}$-bodemoverschot tot gevolg hebben dat op een droge zandgrond (Gt VII) tot overschrijding van de waterkwaliteitsnorm leidt. De gehanteerde norm bedroeg $50 \mathrm{mg}$ nitraat $(11,3 \mathrm{mg} \mathrm{NO}-\mathrm{N}$ ) per liter voor het grondwater onder zandgrond dan wel hangwater onder lössgrond. De vraag van het ministerie beperkte zich tot zand- en lössgrond omdat de voorgestelde $\mathrm{N}$-gebruiksnormen voor klei- en veengrond niet conflicteerden met het op dat moment gehanteerde waterkwaliteitsdoel (11,3 mg N-totaal per liter in nabij oppervlaktewater). Bij de verkenningen ter beantwoording van de vraag van het ministerie is aangenomen dat per regio aan normen voldaan moet worden zodat van de regionale frequentieverdeling van gewassen ('regionale bouwplannen') kon worden uitgegaan. In dat kader is ook uitgegaan van een bepaald ruimtelijk aandeel van natte, matig droge en droge zandgronden en lössgronden. Bij optimale $\mathrm{N}$-bemesting vormde het regionaal gemiddelde opbrengstniveau van gewassen het uitgangspunt. Om de $\mathrm{N}$ - en $\mathrm{P}$ onttrekking te schatten werden gewasopbrengsten met gewasspecifieke maar vaste gehalten vermenigvuldigd. Aangenomen werd dat graanstro en graszaadstro werden afgevoerd. Verder werd in die tijd aangenomen dat de P-voorziening gedekt werd met gemiddeld $100 \mathrm{~kg}$ varkensdrijfmest per hectare, overeenkomend met circa $60 \mathrm{~kg} \mathrm{P}_{2} \mathrm{O}_{5}$ per hectare, in het midden latend welke specifieke gewassen in het regionale bouwplan deze organische mest in meer of in mindere mate ontvingen. Uitgangspunt, voorafgaand aan het te berekenen percentage waarmee de N-gebruiksnorm gekort diende te worden, vormden de $\mathrm{N}$-gebruiksnormen uit 2006 die voor een belangrijk deel zijn gebaseerd op de toenmalige bemestingsrichtlijnen van de LTO-Commissie Bemesting Akkerbouw en Vollegrondsgroenten. Bij de berekeningen werd aan de varkensdrijfmest de op dat moment wettelijke NWC toegekend. Vervolgens werd berekend welke kunstmest-N aanvulling, gegeven de gewasspecifieke $\mathrm{N}$-gebruiksnorm, in beginsel nog gegeven kon worden. Als eindstap volgde een berekening van de korting op de gebruiksnorm die nodig was om op regionaal niveau aan de verlangde nitraat- $\mathrm{N}$ concentratie $(11,3 \mathrm{mg} / \mathrm{l}$ in het ontvangende water) te kunnen voldoen. In eerste

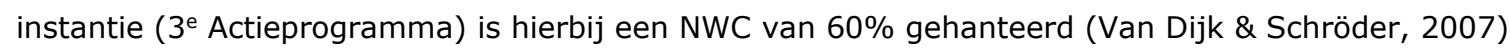
en leidden de berekeningen tot het politieke besluit om de $\mathrm{N}$-gebruiksnorm van uitspoelingsgevoelige gewassen met $0-20 \%$ te korten (Bijlage 2 ). In tweede instantie ( $4^{\mathrm{e}}$ Actieprogramma) is de NWC naar $70 \%$ verhoogd (Schröder et al., 2011) zonder verdere verlaging van de $\mathrm{N}$-gebruiksnormen. In derde instantie ( $5^{\mathrm{e}}$ Actieprogramma) is de NWC van varkensdrijfmest verder verhoogd naar $80 \%$ en zijn de $\mathrm{N}$-gebruiksnormen van uitspoelingsgevoelige gewassen voor zand- en lössgronden met nog eens $20 \%$ (zand- en lössgronden in Limburg en Noord-Brabant) en circa 5\% (overige zand- en lössgronden) verlaagd (Bijlage 2). Het model dat voor de berekeningen gebruikt werd, hanteerde voor het bepalen van de hoeveelheid plantbeschikbare $\mathrm{N}$ in alle gevallen NWC's van $70 \%$ en $80 \%$ voor, respectievelijk, de eerstejaars NWC en de NWC op lange termijn. Deze waarden zijn redelijk in lijn met hetgeen voor bouwland vermeld wordt in Tabel 1 . In de modelmatige verkenningen werd voor de werkelijke beschikbaarheid van $\mathrm{N}$ uit organische mest, evenals bij de verkenningen voor grasland en snijmaïsland, dus uitgegaan van de lange termijn werking. Bij de berekeningen voor gras-en snijmaïsland waren toelaatbaar geachte kunstmest- $\mathrm{N}$ giften een uitkomst van de berekening, geen vertrekpunt. Bij akker- en tuinbouwproducten waren kunstmest- $\mathrm{N}$ giften echter wel het vertrekpunt om te kunnen berekenen welke korting noodzakelijk was om aan milieudoelstellingen te voldoen. De kunstmest-N giften die als vertrekpunt fungeerden werden berekend door van de wettelijke (dus 


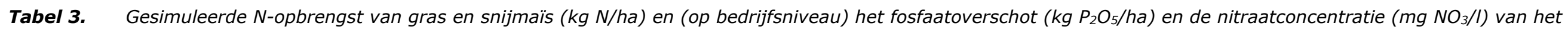

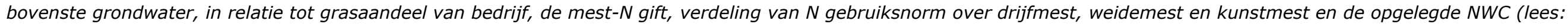

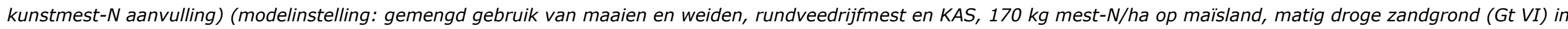
Noord-Nederland, ontijdigheid mineralisatie van $20 \%$ voor gras en $40 \%$ voor snijmaïs).

\begin{tabular}{|c|c|c|c|c|c|c|c|c|c|c|c|c|c|}
\hline \multirow{2}{*}{$\begin{array}{c}\text { Grasaandeel } \\
(\%)\end{array}$} & \multicolumn{2}{|c|}{ N-gebruiksnorm } & \multicolumn{4}{|c|}{ Mestgift (kg N/ha) } & \multirow{2}{*}{$\begin{array}{l}\text { NWC } \\
(\%)\end{array}$} & \multicolumn{2}{|c|}{ KAS (kg N/ha) } & \multicolumn{2}{|c|}{ N-opbrengst } & \multirow{2}{*}{$\begin{array}{l}\text { Fosfaat- } \\
\text { overschot }\end{array}$} & \multirow[t]{2}{*}{ Nitraatconcentratie } \\
\hline & Grasland & Maïsland & Bedrijf & Drijfmest op gras & Weidemest & Drijfmest op maïs & & Gras & Maïs & Gras & Maïs & & \\
\hline 100 & 320 & & 250 & 250 & 0 & & 60 & 170 & & 346 & & -7 & 36 \\
\hline 100 & 250 & & 250 & 240 & 10 & & 45 & 137,5 & & 311 & & 3 & 38 \\
\hline 100 & 250 & & 250 & 180 & 70 & & 45 & 137,5 & & 302 & & 1 & 44 \\
\hline 100 & 320 & & 250 & 250 & 0 & & 80 & 120 & & 324 & & 0 & 23 \\
\hline 100 & 250 & & 250 & 240 & 10 & & 70 & 75 & & 284 & & 11 & 23 \\
\hline 100 & 250 & & 250 & 180 & 70 & & 70 & 75 & & 273 & & 10 & 29 \\
\hline 100 & 320 & & 230 & 230 & 0 & & 60 & 182 & & 345 & & 14 & 34 \\
\hline 100 & 250 & & 230 & 220 & 10 & & 45 & 146,5 & & 308 & & -4 & 35 \\
\hline 100 & 250 & & 230 & 160 & 70 & & 45 & 146,5 & & 299 & & -5 & 41 \\
\hline 100 & 320 & & 230 & 230 & 0 & & 80 & 136 & & 324 & & -8 & 23 \\
\hline 100 & 250 & & 230 & 220 & 10 & & 70 & 89 & & 282 & & 4 & 21 \\
\hline 100 & 250 & & 230 & 160 & 70 & & 70 & 89 & & 272 & & 3 & 28 \\
\hline 80 & 320 & 140 & 250 & 270 & 0 & 170 & 60 & 158 & 38 & 348 & 156 & 2 & 42 \\
\hline 80 & 250 & 140 & 250 & 260 & 10 & 170 & 45 & 128,5 & 63,5 & 314 & 167 & 8 & 47 \\
\hline 80 & 250 & 140 & 250 & 200 & 70 & 170 & 45 & 128,5 & 63,5 & 305 & 167 & 7 & 51 \\
\hline 80 & 320 & 140 & 250 & 270 & 0 & 170 & 80 & 104 & 4 & 325 & 141 & 8 & 28 \\
\hline 80 & 250 & 140 & 250 & 260 & 10 & 170 & 70 & 61 & 21 & 285 & 149 & 16 & 29 \\
\hline 80 & 250 & 140 & 250 & 200 & 70 & 170 & 70 & 61 & 21 & 274 & 149 & 15 & 35 \\
\hline 80 & 320 & 140 & 230 & 230 & 0 & 170 & 60 & 173 & 38 & 346 & 156 & -8 & 40 \\
\hline 80 & 250 & 140 & 230 & 220 & 10 & 170 & 45 & 139,8 & 63,5 & 310 & 167 & 2 & 43 \\
\hline 80 & 250 & 140 & 230 & 160 & 70 & 170 & 45 & 139,8 & 63,5 & 301 & 167 & 0 & 48 \\
\hline 80 & 320 & 140 & 230 & 230 & 0 & 170 & 80 & 124 & 4 & 324 & 141 & -2 & 27 \\
\hline 80 & 250 & 140 & 230 & 220 & 10 & 170 & 70 & 78,5 & 21 & 283 & 149 & 9 & 27 \\
\hline 80 & 250 & 140 & 230 & 160 & 70 & 170 & 70 & 78,5 & 21 & 273 & 149 & 8 & 33 \\
\hline
\end{tabular}


eerstejaars) NWC's voor organische mest uit te gaan. Als de NWC op langere termijn hoger is dan de wettelijk toegekende NWC, dan wordt in principe onnodig veel $\mathrm{N}$ toegepast. In dat geval is een deel van de overschrijding van waterkwaliteitsnormen aan een te laag toegekende NWC toe te schrijven en is dat deel van de milieubelasting te voorkomen door van de lange termijn NWC uit te gaan. Zoals hierboven aangegeven, heeft deze aanpassing bij varkensdrijfmest inmiddels plaatsgevonden. Veranderingen ten aanzien van de vraag naar en het aanbod van soorten mest, hebben er toe geleid dat akker- en tuinbouwbedrijven in plaats van varkensdrijfmest de voorkeur zijn gaan geven aan rundveedrijfmest. Binnen de toegelaten P-gebruiksnorm wordt met deze mestsoort per $\mathrm{kg}_{2} \mathrm{O}_{5}$ een $\mathrm{kg}$ meer $\mathrm{N}$ aangevoerd zonder een navenante korting op de kunstmest- $\mathrm{N}$ gift. Als gevolg hiervan kan bij een overstap van varkensdrijfmest naar rundveedrijfmest meer $\mathrm{N}$ naar het milieu verloren gaan. Scenarioberekeningen (Tabel 4) laten om te beginnen zien dat de gesimuleerde nitraatconcentraties in het bovenste grondwater gemiddeld onder de kwaliteitsdoelstelling van 11,3 mg nitraat- $\mathrm{N}$ per liter zouden blijven als de toenmalige (2006) N-gebruiksnorm volledig met kunstmest- $\mathrm{N}$ zouden worden ingevuld. Dat in de Nitraatrichtlijn Actieprogramma's desondanks besloten is om een korting op de $\mathrm{N}$ gebruiksnorm van uitspoelingsgevoelige gewassen toe te passen, werd ingegeven door de overweging dat de $\mathrm{N}$-gebruiksnorm in de praktijk niet alleen met kunstmest- $\mathrm{N}$ maar ook met organische mest, aanvankelijk varkensdrijfmest, wordt ingevuld. Als gevolg daarvan kwam de gesimuleerde nitraat-N concentratie aanmerkelijk boven de kwaliteitsdoelstelling uit (Tabel 4). Om bij een veronderstelde gift varkensdrijfmest van $100 \mathrm{~kg}$ totaal- $\mathrm{N}$ per hectare toch aan die doelstelling te voldoen, diende de $\mathrm{N}$ gebruiksnorm van uitspoelinggevoelige gewassen volgens het model met $23 \%$ gekort te worden. Dit ging overigens gepaard met een berekende derving van de $\mathrm{N}$-opbrengst van circa $8 \%$. Een korting van $23 \%$ blijkt onvoldoende om ook bij het gebruik van eenzelfde hoeveelheid organische mest- $\mathrm{N}$ in de vorm van rundveedrijfmest aan de waterkwaliteitsdoelstelling te kunnen voldoen. Dit is nog sterker het geval als ruimer bemest wordt, hetgeen als gevolg van de ruimere $\mathrm{N} / \mathrm{P}_{2} \mathrm{O}_{5}$ verhouding van rundveedrijfmest mogelijk is binnen de fosfaatgebruiksnorm (Tabel 4). Om ook bij gebruik van rundveedrijfmest aan de waterkwaliteitsdoelstelling te voldoen is volgens berekening een korting op de $\mathrm{N}$-gebruiksnorm van uitspoelingsgevoelige gewassen nodig die afhankelijk van de mest- $\mathrm{N}$ gift en de toegekende NWC, 29-63\% bedraagt. Dit gaat hoe dan ook gepaard met een extra derving van de Nopbrengst van 5-13\% ten opzichte van de $\mathrm{N}$-opbrengst die (met korting) gerealiseerd wordt bij gebruik van $100 \mathrm{~kg}$ totaal $\mathrm{N}$ per hectare in de vorm van varkensdrijfmest. Verhoging van de wettelijke NWC van rundveedrijfmest van $60 \%$ naar $80 \%$ (lees: minder kunstmest- $\mathrm{N}$ aanvulling) beperkt de omvang van de noodzakelijke korting. Samenvattend:

- $\quad$ het opvullen van de gebruiksnorm met dierlijke mest verhoogt de nitraatconcentratie.

- $\quad$ vervanging van varkensdrijfmest door rundveedrijfmest verhoogt de nitraatconcentratie nog verder.

- $\quad$ de procentuele korting op $\mathrm{N}$-gebruiksnorm die bij gebruik van varkensdrijfmest nodig is om aan de nitraatconcentratie-doelstelling te voldoen, is onvoldoende bij gebruik van rundveedrijfmest.

- de versterkte korting die in dat geval nodig is, kan voorkomen worden door de NWC van rundveedrijfmest van de huidige $60 \%$ naar $80 \%$ te verhogen en tegelijkertijd de mestgift tot circa

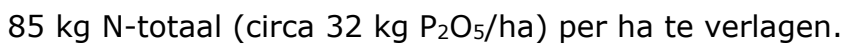

Bij de genoemde verhoging van de NWC naar $80 \%$ komt de waarde ervan op het niveau van de langetermijn $\mathrm{N}$-werking. Een kanttekening is hierbij wel op zijn plaats. Bij een aantal gewassen is het $\mathrm{N}$ advies dat als basis gold voor de gebruiksnorm in 2006, mogelijk ontleend aan proeven die zijn aangelegd op percelen waar het gewas heeft geprofiteerd van de N-nawerking van mestgiften die werden toegediend voor de ingebruikname als proefveld. In dat geval onderschat het geformuleerde $\mathrm{N}$-advies de $\mathrm{N}$-behoefte die in een evenwichtssituatie zou bestaan. Toekenning van een lange termijn NWC zou in dat geval overeenkomen met een dubbeltelling en leiden tot onderschatting van negatieve opbrengstreacties. 
Tabel 4. Gesimuleerd effect van de soort organische mest (dosering $60 \mathrm{~kg} \mathrm{P}_{2} \mathrm{O}_{5} / \mathrm{ha}$, VDM = varkensdrijfmest, RDM = rundveedrijfmest), de wettelijk toegekende $N$-werking (NWC, \%) en de korting (\%) op de $\mathrm{N}$-gebruiksnorm van uitspoelingsgevoelige gewassen, op de opbrengst ( $\mathrm{kg}$ geoogste $\mathrm{N} / \mathrm{ha}$ ), op het fosfaatoverschot ( $\mathrm{kg} \mathrm{P}_{2} \mathrm{O}_{5} / \mathrm{ha}$ ) en op de gemiddelde nitraatconcentratie in het bovenste grondwater ( $\mathrm{mg} \mathrm{NO}_{3} / \mathrm{l}$ ) onder alle akker- en tuinbouwbedrijven op alle zandgronden tezamen.

\begin{tabular}{|c|c|c|c|c|c|c|c|c|}
\hline $\begin{array}{l}\text { Mest- } \\
\text { soort }\end{array}$ & $\begin{array}{l}\text { Wettelijke } \\
\text { NWC (\%) }\end{array}$ & $\begin{array}{c}\mathrm{N} \text {-gift } \\
(\mathrm{kg} / \mathrm{ha}): \\
\text { mest }\end{array}$ & $\begin{array}{c}\text { Korting* } \\
(\%)\end{array}$ & $\begin{array}{c}\text { Kunstmest-N } \\
\text { (kg/ha) }\end{array}$ & $\begin{array}{l}\text { N-oogst } \\
\text { Absoluut } \\
\text { (kg/ha) }\end{array}$ & $\begin{array}{l}\text { Relatief } \\
(\%)\end{array}$ & $\begin{array}{c}\text { Fosfaat- } \\
\text { overschot } \\
\left.\text { (kg } \mathrm{P}_{2} \mathrm{O}_{5} / \mathrm{ha}\right)\end{array}$ & $\begin{array}{l}\text { Nitraat- } \\
\text { concentratie } \\
\text { (mg NO} \\
\text { (m/I) }\end{array}$ \\
\hline- & - & 0 & 0 & 153 & 121 & 103 & -44 & 47 \\
\hline VDM & 80 & 100 & 0 & 73 & 118 & 100 & 13 & 63 \\
\hline RDM & 60 & 100 & 0 & 93 & 120 & 102 & -7 & 77 \\
\hline RDM & 60 & 149 & 0 & 63 & 120 & 102 & 12 & 91 \\
\hline RDM & 80 & 100 & 0 & 73 & 115 & 97 & -5 & 66 \\
\hline RDM & 80 & 149 & 0 & 33 & 112 & 95 & 19 & 75 \\
\hline VDM & 80 & 100 & 23 & 45 & 109 & 92 & 16 & 50 \\
\hline RDM & 60 & 100 & 23 & 66 & 113 & 96 & -4 & 62 \\
\hline RDM & 60 & 149 & 23 & 36 & 113 & 96 & 14 & 77 \\
\hline RDM & 80 & 100 & 23 & 46 & 106 & 90 & -2 & 53 \\
\hline RDM & 80 & 149 & 23 & 6 & 103 & 87 & 18 & 62 \\
\hline VDM & 80 & 100 & 23 & 45 & 109 & 92 & 16 & 50 \\
\hline RDM & 60 & 100 & 46 & 38 & 102 & 86 & -1 & 50 \\
\hline RDM & 60 & $129 *$ & 63 & 0 & 95 & 80 & 13 & 50 \\
\hline RDM & 80 & 100 & 29 & 38 & 103 & 87 & -1 & 50 \\
\hline RDM & 80 & $131 *$ & 41 & 0 & 96 & 81 & 13 & 50 \\
\hline RDM & 80 & 85 & 23 & 58 & 107 & 91 & -8 & 50 \\
\hline
\end{tabular}

* In deze situaties moet de mestgift worden beperkt ( $<60 \mathrm{~kg} \mathrm{P} \mathrm{P}_{5} / \mathrm{ha}$ ) om geen negatieve kunstmest- $\mathrm{N}$ giften te hoeven opleggen en toch aan de waterkwaliteitsdoelstelling te kunnen voldoen. 


\section{$7 \quad$ Compost en vaste mest}

Zoals eerder aangegeven gebruiken de landbouwvoorlichting en overheid met name de eerstejaars Nwerking van dierlijke mest (Tabel 1 ) terwijl herhaald gebruik van mest eerder regel dan uitzonding is. Een relevante vraag daarbij is na hoeveel herhaalde giften met die lange termijn $\mathrm{N}$-werking landbouwkundig mág en milieukundig móet worden rekeningen gehouden. Deze vraag is relevanter naarmate een organische mest per $\mathrm{kg} \mathrm{N}$-totaal of per $\mathrm{kg}_{2} \mathrm{O}_{5}$ meer langzaam afbreekbare organische $\mathrm{N}$ bevat (recalcitrante $\mathrm{N}, \mathrm{Nr}$ ), zoals het geval is bij compost en in mindere mate bij vaste mesten (Tabel 5). Overigens kan hieraan worden toegevoegd dat de N-giften die in de praktijk in de vorm van compost of vaste mest worden gegeven vooralsnog beperkt zullen blijven. Dit volgt uit hun beperkte productie en hun beperkte $\mathrm{N}$-inhoud per $\mathrm{kg}$ toe te dienen $\mathrm{P}_{2} \mathrm{O}_{5}$. In Nederland wordt jaarlijks namelijk ongeveer 2 miljoen ton compost geproduceerd (BVOR, 2018). Als deze compost volledig op alleen bouwland zou worden toegediend komt dat overeen met gemiddeld 2-3 ton compost per hectare. Die gift vertegenwoordigt een dosering van circa $20 \mathrm{~kg} \mathrm{~N}$-totaal per hectare. Veronachtzaming van de $\mathrm{N}$-nalevering zou het landbouwkundige $\mathrm{N}$-effect op (zeer) lange termijn met een kleine $10 \mathrm{~kg} \mathrm{~N}$ per hectare per jaar onderschatten (NWC stijgt van circa $10 \%$ in het eerste jaar van toediening naar ruim $50 \%$ bij langdurig herhaald gebruik). De fractie uitspoelbare $\mathrm{N}$ zou toenemen van $5 \%$ in het eerste jaar van toediening naar $45 \%$ bij langdurig herhaald gebruik, ofwel $8 \mathrm{~kg}$ meer uitspoelbare $\mathrm{N}$ per ha bij een GFT gift van $20 \mathrm{~kg} \mathrm{~N}$-totaal per ha.

Tabel 5. Het aandeel organisch gebonden $N(\mathrm{Norg}=\mathrm{Ne}+\mathrm{Nr})$ en langzaam afbreekbare organische $N$ (recalcitrante $\mathrm{N}, \mathrm{Nr}$ ) per $\mathrm{kg} \mathrm{N}$-totaal en per $\mathrm{kg} \mathrm{P}_{2} \mathrm{O}_{5}$ bij verschillende mestsoorten (bron: www.bemestingsadvies. $n l)$.

\begin{tabular}{lcccc} 
Mestsoort & Norg / N-total & Norg/ $\mathrm{P}_{2} \mathrm{O}_{5}$ & $\mathrm{Nr} / \mathrm{N}$-totaal & $\mathrm{Nr} / \mathrm{P}_{2} \mathrm{O}_{5}$ \\
Vleesvarkensdrijfmest & 0,48 & 0,86 & 0,16 & 0,28 \\
\hline Rundveedrijfmest & 0,52 & 1,39 & 0,36 & 0,97 \\
\hline Vaste vleesvarkensmest & 0,67 & 0,67 & 0,22 & 0,22 \\
\hline Vaste rundveemest & 0,86 & 1,54 & 0,60 & 1,08 \\
\hline Groencompost & 0,90 & 2,04 & 0,81 & 1,84 \\
\hline GFT-compost & 0,91 & 1,85 & 0,82 & 1,66 \\
\hline Champost & 0,95 & 1,61 & 0,48 & 0,80 \\
\hline
\end{tabular}

Net als bij compost, is ook de beschikbaarheid van vaste mest zeer beperkt. Berekend op basis van de $\mathrm{N}$-inhoud bestaat niet meer dan $5 \%$ van de geproduceerde rundveemest uit vaste mest. Voor de andere twee belangrijke vaste mestsoorten, varkensmest en pluimveemest, bestaan deze aandelen uit, respectievelijk, $1 \%$ en $100 \%$ (CBS, persoonlijke mededeling C. van Bruggen). Overwegende dat een belangrijk deel van de pluimveemest niet binnen Nederland wordt uitgereden maar centraal verbrand, vertegenwoordigt de vaste mest een gift van gemiddeld niet meer dan ongeveer $10 \mathrm{~kg} \mathrm{~N}$ per hectare Nederlandse landbouwgrond. De milieueffecten van deze mesten zijn, ongeacht de er aan toegekende NWC, zeer beperkt. 


\section{Eerstejaars $\mathrm{N}$-werking vertekent effecten}

Uit organische mest komt een aantal nutriënten, waaronder $N$, geleidelijk vrij. Die zogenaamde mineralisatie strekt zich meestal uit over vele jaren. De $\mathrm{N}$ beschikbaarheid voor een gewas laat zich daarom niet in éénjarige veldproeven bepalen. Bij herhaalde toediening van organische mest, meer regel dan uitzondering, laten de staartjes nawerking zich bij elkaar optellen en komen de jaarlijkse aanvoer van organische stof (en de $\mathrm{N}$ daarin) en de jaarlijkse mineralisatie van de organische stof op een gegeven moment met elkaar in evenwicht. Overigens zal de cumulatieve mineralisatie de jaarlijkse aanvoer aanvankelijk overtreffen in systemen waar, bijvoorbeeld als gevolg van aanscherpende wetgeving, in de loop van de jaren betekenisvol minder organische mest is toegediend. De omvang van dit effect is echter beperkt. Een verlaging van de organische mestgift met $10 \mathrm{~kg} \mathrm{P} \mathrm{O}_{5}$ per hectare leidt bij varkensdrijfmest $\left(\mathrm{N} / \mathrm{P}_{2} \mathrm{O}_{5}=1,79\right.$, Norg/Ntot $=0,48, \mathrm{HC}=0,33$ (bron: Anonymus, 2019)) tot een daling van de mineralisatie met maximaal $3 \mathrm{~kg} \mathrm{~N}$ per hectare per jaar (waarvan circa $2 \mathrm{~kg} \mathrm{~N}$ per ha binnen het groeiseizoen). De overeenkomstige daling bij rundveedrijfmest $\left(\mathrm{N} / \mathrm{P}_{2} \mathrm{O}_{5}=2,67\right.$, Norg/Ntot $=0,52, \mathrm{HC}=0,70$ (bron: Anonymus, 2019)) bedraagt maximaal $10 \mathrm{~kg} \mathrm{~N}$ per hectare per jaar (waarvan circa $5 \mathrm{~kg} \mathrm{~N}$ per ha binnen het groeiseizoen). Ondanks de decennia-lange toediening van organische mest, ligt in de landbouwvoorlichting het accent toch vooral op de eerstejaars N-werking van mest. Dit is mogelijk ingegeven door het beeld uit de gebruikelijke éénjarige veldproeven. Het Nederlandse mestbeleid en de regelgeving daaromtrent sluiten hier ten dele bij aan. Bij een veel gebruikte organische mest als rundveedrijfmest zijn telers er immers wettelijk aan gehouden om de eerstejaars NWC in rekening te brengen. Dat geldt ook voor compost. Vanuit een landbouwkundig oogpunt is het logisch de toegekende NWC aan te laten sluiten bij het doorgaans herhaalde gebruik van organische mest en dus steeds uit te gaan van de $\mathrm{N}$-werking op lange termijn. Daarbij is wel aandacht nodig voor het gevaar van dubbeltelling. Zo is het niet correct om te rekenen met de lange termijn $\mathrm{N}$-werking van organische mest maar de kunstmest- $\mathrm{N}$ aanvullingen tegelijkertijd naar beneden aan te passen op basis van een gemeten (www.bemestingsadvies. $\mathrm{nl}$ ) verhoogd N-leverend vermogen (NLV) van de bodem. In dat NLV ligt de $\mathrm{N}$-nawerking van eerder gegeven organische mest immers besloten. Daarbij kan wel worden aangetekend dat de CBGV zich op dit moment beraadt over de vraag of het NLV onderdeel van de bemestingsadvisering moet blijven. Een verkapte vorm van dubbeltelling kan ook bij bouwlandgewassen optreden. Bij een aantal gewassen is het $\mathrm{N}$-bemestingsadvies mogelijk afgeleid uit veldproeven waar vóór aanleg van de proef volgens de praktijk organische mest is toegediend. Als gevolg daarvan profiteerde het gewas in zo'n proef van N-nawerking en werd de werkelijke N-behoefte misschien onderschat. Toepassing van de lange termijn NWC in praktijksituaties zou het desbetreffende gewas, landbouwkundig althans, te kort doen. Overigens is het lastig na te gaan voor welke gewassen en, zo ja, hoezeer de $\mathrm{N}$-adviezen met dit verschijnsel van een miskende $\mathrm{N}$-nawerking behept zijn. Op dit moment kijkt de CBAV naar de mogelijkheden van een andere systematiek voor ontwikkeling van N-bemestingsadviezen waar dit soort verstrengelingen minder inzitten. Globaal betekent dit dat de gewasbehoefte op basis van een bepaalde N-opnamecapaciteit en -recovery wordt bepaald en waarvan verschillende aanvoerposten (w.o. nawerking, depositie, e.d.) expliciet worden ingerekend.

\section{Andere mestsoort, andere $\mathrm{N}$-gebruiksnorm}

In het N-gebruiksnormen stelsel bepalen de opgelegde NWC's hoeveel kunstmest- $\mathrm{N}$ naast organische mest gegeven kan worden. De consequentie daarvan is dat de bemesting van een gewas uit sterk van elkaar verschillende combinaties van kunstmest-N, van (verzamelde, bewaarde, bewerkte) organische mesten en van eventuele weidemest kunnen bestaan. Al die combinaties zijn invullingen van een en dezelfde $\mathrm{N}$-gebruiksnorm. Hoewel milieudoelen de aanleiding vormen voor het vaststellen van $\mathrm{N}$ gebruiksnormen, leidt elk van de voornoemde combinaties binnen eenzelfde $\mathrm{N}$-gebruiksnorm tot een andere milieukwaliteit. Om te bewerkstelligen dat elke denkbare combinatie tot eenzelfde milieukwaliteit leidt, zou eigenlijk per combinatie een $\mathrm{N}$-gebruiksnorm moeten worden gedefinieerd. Een besluit daartoe heeft vanzelfsprekend gevolgen voor de administratieve druk en 
handhaafbaarheid. Vanuit dat oogpunt kan besloten worden om een eventuele differentiatie van $\mathrm{N}$-gebruiksnormen te beperken tot de meest voorkomende combinaties. Een voorbeeld daarvan is het globale onderscheid tussen bedrijven die hun grasland alleen maaien en bedrijven die hun grasland daarnaast ook beweiden. Voor akker- en tuinbouwbedrijven zijn de N-gebruiksnormen indertijd geënt op maar één combinatie van mest en kunstmest. Het vertrekpunt vormde immers een bedrijf dat zijn fosfaatruimte (toestand neutraal: $60 \mathrm{~kg} \mathrm{P}_{2} \mathrm{O}_{5}$ per hectare per jaar) volledig dekt met varkensdrijfmest met gemiddelde verhoudingen van minerale $\mathrm{N}$, organische $\mathrm{N}$ en $\mathrm{P}_{2} \mathrm{O}_{5}$, in de veronderstelling dat die mestsoort indertijd de meest gebruikelijke was. Inmiddels heeft deze mestsoort naar verluidt plaats gemaakt voor de dunne fractie van varkensmest, voor rundveedrijfmest of voor combinaties van die twee. Als de fosfaatruimte met rundveedrijfmest gedekt wordt, kan ook de N-gebruiksnorm vanwege de ruimere $\mathrm{N} / \mathrm{P}_{2} \mathrm{O}_{5}$ verhouding meer met organische mest worden ingevuld en is de milieubelasting groter dan bij gebruik van varkensdrijfmest of de dunne fractie daarvan. Om in die situatie alsnog aan een waterkwaliteitsdoelstelling te kunnen voldoen, zou de $\mathrm{N}$-gebruiksnorm moeten worden verlaagd en/of de NWC moeten worden verhoogd. Voor dat laatste is hoe dan ook aanleiding om recht te doen aan het doorgaans herhaalde gebruik. Dan nog geven modelberekeningen aan dat de nitraatuitspoeling bij gebruik van rundveedrijfmest hoger is dan bij gebruik van varkensdrijfmest bij een zelfde mest-N-dosering. Dit komt doordat rundveedrijfmest verhoudingsgewijs meer organische $\mathrm{N}$ bevat en minder ammonium- $\mathrm{N}$ waardoor eenzelfde hoeveelheid mest- $\mathrm{N}$ bij rundveedrijfmest een hoger bodem-N-overschot (mindere ammoniakverliezen) en een hogere nitraatconcentratie tot gevolg heeft. In plaats van een verlaging van de $\mathrm{N}$-gebruiksnorm kan ook een beperking van de dosering van rundveedrijfmest de gewenste waterkwaliteit helpen realiseren. Een degelijke beperking kan nadelig zijn voor de aanvoer van effectieve organische stof via organische mest. Waar een bepaalde aanvoer van effectieve organische stof noodzakelijk geacht wordt, is een aanpassing van het bouwplan dan onvermijdelijk. Daarbij kan het ook noodzakelijk worden meer groenbemesters te telen of graanstro achter te laten.

Stikstofgebruiksnormen zijn idealiter gebaseerd op een analyse die gericht is op het identificeren van combinaties van hoeveelheden $\mathrm{N}$ uit organische mest en kunstmest die de gewasopbrengst maximaliseren zonder daarbij milieudoelen te overschrijden. Vervolgens dient de organische mestgift van elke combinatie vermenigvuldigd te worden met een NWC waarna de som van de plantbeschikbare N (NWC * mest- $\mathrm{N}$ ) uit organische mest en de kunstmest- $\mathrm{N}$ de $\mathrm{N}$-gebruiksnorm vormt. Dit is in grote trekken de werkwijze geweest bij de totstandkoming van de $\mathrm{N}$-gebruiksnormen van grasland en snijmaïs. Vervanging van de eerstejaars NWC van rundveedrijfmest door een lange termijn NWC kan hand in hand gaan met een verhoging van de $\mathrm{N}$-gebruiksnorm omdat het milieuresultaat er niet anders van wordt.

Bij akker- en tuinbouwgewassen is de situatie anders. Een uniform gebruik van varkensdrijfmest vormde daar het vertrekpunt bij de totstandkoming van de $\mathrm{N}$-gebruiksnormen. Vervanging van varkensdrijfmest met een wettelijke NWC van $80 \%$ door rundveedrijfmest met een huidige wettelijke NWC van $60 \%$ komt overeen met een verruiming van de mogelijkheid om met kunstmest- $\mathrm{N}$ aan te vullen. Dit kan worden voorkomen door ook aan rundveedrijfmest een lange termijn NWC van $80 \%$ toe te kennen. Anders dan bij grasland en maïsland vormt een verhoging van de NWC dan ook geen aanleiding om tegelijkertijd de $\mathrm{N}$-gebruiksnorm van akker- en tuinbouwgewassen te verhogen. Dit is temeer niet het geval omdat met rundveedrijfmest per $\mathrm{kg}$ fosfaatruimte circa $60 \%$ meer organische mest-N toegediend kan worden.

\section{Update van gebruiksnormenstelsel}

In het voorgaande is ingegaan op de vraag of wijzigingen van de NWC aanleiding zouden moeten zijn om ook de N-gebruiksnormen te wijzigen. Omwille van de volledigheid wordt hier ook nog gewezen op andere overwegingen om $\mathrm{N}$-gebruiksnormen aan te passen. In de loop van de jaren zijn diverse parameter-waarden van de gebruikte modellen gewijzigd op basis van nieuwe metingen en waarnemingen. Dit betreft opbrengstniveaus, N- en P-gehalten, bouwplansamenstellingen, uitspoelfracties, neerslagoverschotten, de verdeling van gronden over droogteklassen, de gebruikte mestsoorten en hun samenstelling. Het is op voorhand niet te zeggen wat het gecombineerde effect van al deze wijzigingen op de milieukwaliteit zal zijn en of dit gevolgen zou moeten hebben voor de gebruiksnormen. Het is daarom verstandig om het gebruiksnormenstelsel van tijd tot tijd te updaten. Afhankelijk van eventueel te maken keuzes over de mate waarin gebruiksnormen bedrijf- of perceelspecifieker zouden moeten zijn, valt ook nog te denken aan een verdere verbijzondering van het lot van $\mathrm{N}$-bodemoverschot. Dat gesimuleerde lot is volgens de tot nu toe gebruikte rekenregels niet 
afhankelijk gemaakt van de aard van het $\mathrm{N}$-bodemoverschot. In plaats daarvan wordt bij de berekening een factor met een gemiddelde waarde gebruikt terwijl voorstelbaar is dat de milieubelasting en in het bijzonder de $\mathrm{N}$-uitspoeling van, zeg, $100 \mathrm{~kg} \mathrm{~N}$ in bietenblad iets minder is dan die gemiddelde waarde en de milieubelasting van $100 \mathrm{~kg} \mathrm{~N}$ in de vorm van minerale bodem- $\mathrm{N}$ iets meer is dan die gemiddelde waarde. Dat kan tot gevolg hebben dat de uitspoeling onder een bedrijf met relatief veel suikerbieten enigszins overschat wordt en de uitspoeling onder een bedrijf met, bijvoorbeeld, relatief veel aardappelen enigszins onderschat. Berekeningen gaan ook voorbij aan de mogelijkheid dat sommige mestsoorten onder bepaalde omstandigheden de omzetting van uitspoelbare $\mathrm{N}$ in gasvormige $\mathrm{N}_{2}$ en $\mathrm{N}_{2} \mathrm{O}$ bevorderen (zie paragraaf 2 ). Als in het kader van een perceel- en bedrijf-specifiekere benadering aan sommige bedrijven meer bemestingsruimte wordt toegekend omdat ze milieudoelen niet overschrijden, zal op een grotere ruimtelijke schaal alleen dan aan milieudoelen kunnen blijven worden voldaan, als tegelijkertijd aan andere bedrijven minder bemestingsruimte wordt gegund. Overschrijding van milieudoelen door laatstgenoemde bedrijven wordt dan immers niet langer gecompenseerd door een onderschrijding elders.' 


\section{Aanbevelingen}

- Verhoging van de N-werkingscoëfficiënt van vloeibare dierlijke mest naar $70-80 \%$ en van vaste dierlijke mest naar 55-75\% komt beter overeen met de werkelijkheid, ook bij melkveebedrijven met beweiding,

- Bij grasland en maïsland zou een dergelijke verhoging geen effect moeten hebben op de mogelijkheid om met kunstmest- $\mathrm{N}$ aan te vullen en dienen dan dus ook de $\mathrm{N}$-gebruiksnormen verhoogd te worden,

- Bij akker- en tuinbouwgewassen moet een verhoging van $\mathrm{N}$-werkingscoëfficiënten van dierlijke mest, anders dan bij de gewassen gras en maïs, niet gepaard gaan met een verhoging van de $\mathrm{N}$ gebruiksnormen,

- Eén en dezelfde N-gebruiksnorm kan met tal van combinaties van kunstmest, drijfmest, stalmest, weidemest en/of compost worden ingevuld en milieuresultaten (waaronder de gerealiseerde nitraatconcentraties in water) van elk van die combinaties verschillen daarom ook. nog los van de effecten die opbrengsten, grondsoorten of toegekende $\mathrm{N}$-werkingscoëfficiënten daarop hebben. Als om die reden $\mathrm{N}$-gebruiksnormen van combinaties met een beperkte milieubelasting verhoogd zouden worden, kan op een grotere ruimtelijke schaal alleen dan een bepaald milieuresultaat voldaan blijven worden als de $\mathrm{N}$-gebruiksnormen van combinaties met een relatief hoge milieubelasting tegelijkertijd verlaagd wordt,

- Vereenvoudiging en verfijning van regelgeving rond het gebruik van meststoffen staan op gespannen voet met elkaar. 


\section{Literatuur}

Anonymus, 2019. Samenstelling organische meststoffen. Brancheorganisatie Akkerbouw, https://www.handboekbodemenbemesting.nl

BVOR, 2018. https://bvor.nl/download/marktcijfers-producten-uit-groene-reststromen-in-2017/, 3 pp. ‘

Cameron, K.C., J.J. Di \& J.L. Moir, 2013. Nitrogen losses from the soil-plan system: a review. Annals of Applied Biology 162, 145-173.

CDM, 2017. Advies CDM werkingscoëfficiënt graasdiermest. Commissie Deskundigen Meststoffenwet, Wageningen, $16 \mathrm{pp}$.

Christensen, S., 1985. Denitrification in an acid soil: effects of slurry and potassium nitrate on the evolution of nitrous oxide and on nitrate reducing bacteria. Soil Biology and Biochemistry 17, $757-$ 764.

Ciarlo, E., M. Conti, N. Bartoloni \& G. Rubio, 2008. Soil $\mathrm{N}_{2} \mathrm{O}$ emissions and $\mathrm{N}_{2} \mathrm{O} /\left(\mathrm{N}_{2} \mathrm{O}+\mathrm{N}_{2}\right)$ ratio as affected by different fertilization practices and soil moisture. Biology and Fertility of Soils 44 (7), 991-995.

Ellis, S., S. Yamulki, E. Dixon, R. Harrison \& S.C. Jarvis, 1998. Denitrification and $\mathrm{N}_{2} \mathrm{O}$ emissions from a UK pasture soil following the early spring application of cattle slurry and mineral fertiliser. Plant and Soil 202, 15-25.

Geurink, J.H. \& H.G. van der Meer, 1995. De stikstofwerking van verschillende soorten dunne mest bij verschillende toedieningstechnieken op grasland. Rapport 42. AB-DLO, Wageningen, The Netherlands, $37 \mathrm{pp}$.

Huijsmans, J.F.M., J.J. Schröder, J. Mosquera, G.D. Vermeulen, H.F.M. ten Berge \& J.J. Neeteson, 2016. Should low-emission regulations for land-application of manures in the Netherlands be reconsidered? Soil Use and Management 32: 109-116.

McGeough, K.L., R.J. Laughlin, C.J. Watson, C. Mueller, M. Ernfors, E. Cahalan \& K.G. Richards, 2012. The effect of cattle slurry in combination with nitrate and the nitrification inhibitor dicyandiamide on in situ nitrous oxided and denitrogen emissions. Biogeoscienes 9, 4909-4919.

Paul, J.W. \& B.J. Zebarth, 1997. Denitrification during the growing season following dairy cattle slurry and fertilizer application for silage corn. Canadian Journal of Soil Science 77 (2), 241-248.

Rochette, P., E. van Bochove, D. Prevost, D.A. Angers, D. Cote \& N. Bertrand, 2000. Soil carbon and nitrogen dynamics following application of pig slurry for the 19th consecutive year: II Nitrous oxide fluxes and mineral nitrogen. Soil Sci. Soc. Am. J. 64, 1396-1403.

RVO, 2018. https://www.rvo.nl/sites/default/files/2018/03/Tabel-3-Werkingscoefficient-dierlijke-enandere-organische-meststoffen-2018_0.pdf (raadpleging op 16 januari 2019)

Schils, R.L.M. \& I. Kok, 2003. Effects of cattle slurry manure management on grass yield. Netherlands Journal of Agricultural Science 51, 41-65.

Schils, R.L.M., J.W. van Groeningen, G.L. Velthof \& P.J. Kuikman, 2008. Nitrous oxide emissions from multiple combined applications of fertiliser and cattle slurry to grassland. Plant and Soil 310, 89101.

Schröder, J.J., 2005. Manure as a suitable component of precise nitrogen nutrition. Proceedings 574, International Fertiliser Society, $32 \mathrm{pp}$.

Schröder, J.J. \& J.C. van Middelkoop, 2016. Verdeling van beschikbare $\mathrm{N}$ uit drijfmest over het seizoen op grasland. Notitie LTO-Commissie Bemesting Grasland en Voedergewassen, Wageningen, 8 pp.

Schröder, J.J., A.G. Jansen \& G.J. Hilhorst, 2005a. Long term nitrogen fertilizer value of cattle slurry. Soil Use and Management 21, 196-204.

Schröder, J.J., H. van Schooten, M. Bruinenberg \& W. van Dijk, 2005b. De stikstofwerkingscoëfficiënt van organische mest op maïsland; Berkendijk 1988-2002. Rapport 101, PRI, Wageningen, 19 pp.

Schröder, J.J., H.F.M. Aarts, J.C. van Middelkoop, M.H.A. de Haan, R.L.M. Schils, G.L. Velthof, B. Fraters \& W.J. Willems, 2005c. Limits to the use of manure and mineral fertilizer in grass and silage maize production, with special reference to the EU Nitrates Directive. Report 93, Plant Research International, Wageningen, $48 \mathrm{pp}$. 
Schröder, J.J., D Uenk, \& G.J. Hilhorst, 2007a. Long-term nitrogen fertilizer replacement value of cattle manures applied to cut grassland. Plant \& Soil 299: 83-99.

Schröder, J.J., H.F.M. Aarts, J.C. van Middelkoop, R.L.M. Schils, G.L. Velthof, B. Fraters \& W.J. Willems, 2007b. Permissible manure and fertilizer use in dairy farming systems on sandy soils in The Netherlands to comply with the Nitrates Directive target. European Journal of Agronomy 27, 102-114.

Schröder, J.J., J.C. van Middelkoop, W. van Dijk en G.L. Velthof, 2008b. Quick Scan aangaande de Stikstofwerking van Dierlijke Mest -actualisering van kennis en de mogelijke gevolgen van aangepaste forfaits, Wageningen, Wettelijke Onderzoekstaken Natuur \& Milieu, WOt-rapport 85, $55 \mathrm{pp}$.

Schröder, J.J., H.F.M. Aarts, J.C. van Middelkoop, G.L. Velthof, J.W. Reijs \& B. Fraters. 2009. Nitrates Directive requires limited inputs of manure and mineral fertilizer in dairy farming systems. Report 222. Plant Research International, Wageningen, The Netherlands, $37 \mathrm{pp}$

Schröder, J.J., F. Assinck, D. Uenk \& G.L. Velthof, 2010. Nitrate loss from grassland on sandy soils, as affected by the substitution of manure $\mathrm{N}$ for mineral fertilizer $\mathrm{N}$ and by soil type. Grass and Forage Science 65: 49-57.

Schröder, J.J., W. van Dijk \& H. Hoek, 2011. Modelmatige verkenningen naar de relaties tussen stikstofgebruiksnormen en de waterkwaliteit van landbouwbedrijven. Rapport 415, Plant Research International, Wageningen UR, Wageningen, $52 \mathrm{pp}$.

Schroder, J.J., W. de Visser, F.B.T. Assinck \& G.L. Velthof, 2013a. Effects of short-term nitrogen supply from livestock manures and cover crops on silage maize production and nitrate leaching. Soil Use and Management 29 (2), 151-160.

Schröder, J.J., L. Bechini, S. Bittman, M. Brito, S. Delin, S. Lalor, T. Morvan, B. Chambers, R. Sakrabani \& P. Sørensen, 2013b. Residual N effects from livestock manure inputs to soils. In: Proceedings 15th International Ramiran Conference, Versailles, France, 3-5 June 2013.

Senbayram, M., R. Chen, A. Budai, L. Bakken \& K. Dittert, 2012. $\mathrm{N}_{2} \mathrm{O}$ emission and the $\mathrm{N}_{2} \mathrm{O} /\left(\mathrm{N}_{2} \mathrm{O}+\right.$ $\mathrm{N}_{2}$ ) product ratio of denitrification as controlled by available carbon substrates and nitrate concentrations. Agric. Ecosys. Environ. 147, 4-12.

Thompson, R.B., 1989. Denitrification in slurry-treated soil: occurrence at low temperatures, relationship with soil nitrate and reduction by nitrification inhibitors. Soil Biol. Biochem. 21, 875882.

Vallejo, A., J.A. Diez, L.M. Lopez-Valdivia, M.C. Cartagena, A. Tarquis \& P. Hernaiz, 2004. Denitrification from an irrigated soil fertilized with pig slurry under Mediterranean conditions. Biol. Fertil. Soils 40, 93-100.

Van Bruggen, C., 2018. Dierlijke mest en mineralen 2017. CBS, Den Haag, 42 pp.

Van Dijk, W. \& J.J. Schröder, 2007. Adviezen voor stikstofgebruiksnormen voor akker- en tuinbouw op zand- en loessgrond bij verschillende uitgangspunten. Rapport 371, PPO Lelystad, 78 pp.

Van Dijk, W., J.G. Conijn, J.F.M. Huijsmans, J.C. van Middelkoop \& K.B. Zwart, 2004. Onderbouwing $\mathrm{N}$-werkingscoëfficiënt organische mest. Rapport 337, PPO, Lelystad, 63 pp

Van Dijk, W., A.M. van Dam, J.C. van Middelkoop, F.J. de Ruijter \& K.B. Zwart, 2005. Onderbouwing $\mathrm{N}$-werkingscoëfficiënt overige organische meststoffen. Rapport 343, PPO, Lelystad, 42 pp

Velthof, G.L., P.J. Kuikman \& O. Oenema, 2003. Nitrous oxide emission from animals manures applied to soil under controlled conditions. Biol. Fertil. Soils 37, 221-230.

Velthof, G.L., O. Oenema, R. Postma \& M.L. van Beusichem, 1997. Effect of type and amount of applied nitrogen fertilizer type on nitrous oxide fluxes from intensively managed grassland. Nutrient Cycling in Agroecosystems 46, 257-267.

Velthof, G.J. \& R.M.J.J. Rietra, 2018. Nitrous oxide emission from agricultural soils. WEnR report 2921, Wageningen UR, Wageningen, $57 \mathrm{pp}$.

Webb, J., P. Sörensen, G. Velthof, B. Amon, M. Pinto, L. Rodhe, E. Salomon, N. Hutchings, P. Burczyk $\& \mathrm{~J}$. Reid, 2013. An assessment of the variation of manure nitrogen efficiency throughout Europe and an appraisal of means to increase manure- $N$ efficiency. Advances in Agronomy, 119: 371-442.

Zaman, M., M.L. Nguyen, M. Šimek, S. Nawaz, M.J. Khan, M.N. Babar \& S. Zaman, 2012. Emissions of Nitrous Oxide $\left(\mathrm{N}_{2} \mathrm{O}\right)$ and Di-Nitrogen $\left(\mathrm{N}_{2}\right)$ from the Agricultural Landscapes, Sources, Sinks, and Factors Affecting $\mathrm{N}_{2} \mathrm{O}$ and $\mathrm{N}_{2}$ Ratios. In: Guoxiang Liu (Ed.) Greenhouse Gases - Emission, Measurement and Management. INTECH, http://www.intechopen.com/books/greenhousegases, pp. 3-24. 
Bijlage 1 Protocol ter uniforme bepaling van de landbouwkundige Nwerking en het milieukundige lot van organische mest in het eerste jaar na toediening en op lange termijn

berekening NWC's van diverse mestsoorten toegediend op grasland (zie voor rekenregels Protocol 1.9)

\begin{tabular}{|c|c|c|c|c|c|c|c|c|}
\hline & $\begin{array}{l}\text { Grondgebruik } \\
\text { Mestsoort }\end{array}$ & $\begin{array}{l}\text { Grasland } \\
\text { Rundergier }\end{array}$ & Dunne fractie, rund & Rundveedrijfmest & Digestaat & Dikke fr, rund & Rundveevastemest & Weidemest \\
\hline A & Ammonium-N aandeel in totale $\mathrm{N}$ inhoud, \% & 95 & 60 & 48 & 65 & 22 & 14 & 50 \\
\hline в & Ammoniakverlies per $\mathrm{kg}$ toegediende ammonium- $\mathrm{N}, \%$ & 8 & 19 & 19 & 19 & 74 & 74 & 2 \\
\hline c & humificatiecoëfficiënt, \% & 70 & 70 & 70 & 70 & 70 & 70 & 70 \\
\hline D & tijdigheid van mineralisatie, \% & 90 & 90 & 90 & 90 & 90 & 90 & 90 \\
\hline $\mathrm{E}$ & extra $\mathrm{N}$-verlies door denitrificatie per kg toegediende $\mathrm{N}$ (na aftrek van ammoniak-N verlies), \% & 0 & 0 & 0 & 0 & 0 & 0 & 0 \\
\hline $\mathrm{F}$ & relatieve efficiëntie van mest- $\mathrm{N}$ in eerste jaar na toediening & 100 & 100 & 100 & 100 & 100 & 100 & 25 \\
\hline G & NWC (\%) in eerste jaar van toediening & 89 & 59 & 53 & 62 & 27 & 27 & 16 \\
\hline H & NWC (\%) bij herhaald gebruik op langere termijn & 92 & 85 & 86 & 84 & 76 & 81 & 47 \\
\hline 1 & Fracie (\%) van toegediende totale $\mathrm{N}$ gift als ammoniak-N verloren & 7.6 & 11.4 & 9.1 & 12.4 & 16.3 & 10.4 & 1.0 \\
\hline j & Fractie (\%) van toegediende totale $\mathrm{N}$ gift buiten opname-seizoen gemineraliseerd in eerste 12 maanden & 0.2 & 1.2 & 1.6 & 1.1 & 2.3 & 2.6 & 1.5 \\
\hline K & idem, op langere termijn & 0.5 & 4.0 & 5.2 & 3.5 & 7.8 & 8.6 & 5.0 \\
\hline L & Fractie (\%) van toegediende totale $\mathrm{N}$ gift niet voor gewas beschikbaar a.g.v. extra (kennelijke) denitrificatie in eerste 12 maanden en/of (in)efficiëntie & 0.0 & 0.0 & 0.0 & 0.0 & 0.0 & 0.0 & 46.9 \\
\hline M & idem, op langere termijn & 0.0 & 0.0 & 0.0 & 0.0 & 0.0 & 0.0 & 46.9 \\
\hline \multirow[t]{2}{*}{$\mathrm{N}$} & Fractie (\%) van toegediende totale $\mathrm{N}$ gift nog niet gemineraliseerd in eerste 12 maanden & 3.5 & 28.0 & 36.4 & 24.5 & 54.6 & 60.2 & 35.0 \\
\hline & $\begin{array}{ll}\text { CHECK } & \text { eerste jaar } \\
\end{array}$ & 100 & 100 & 100 & 100 & 100 & 100 & 100 \\
\hline
\end{tabular}


berekening NWC's van diverse mestsoorten toegediend op bouwland (zie voor rekenregels Protocol 1.9)

\begin{tabular}{|c|c|c|c|c|c|c|c|c|c|c|c|}
\hline & $\begin{array}{l}\text { Grondgebruik } \\
\text { Mestsoort } \\
\end{array}$ & $\begin{array}{l}\text { Bouwland } \\
\text { Varkensdrijfmest }\end{array}$ & Rundveedrijfmest & Rundveevastemest & Varkensvastemest & GFT compost & Dunne fractie, varken & Dunne fractie, rund & Dikke fractie, varken & Dikke fractie, rund & Digestaat, rund \\
\hline A & zie voor betekenis Protocol 1.1 & 52 & 48 & 14 & 33 & 9 & 64 & 60 & 29 & 22 & 65 \\
\hline B & zie voor betekenis Protocol 1.1 & 2 & 2 & 22 & 22 & 22 & 2 & 2 & 22 & 22 & 2 \\
\hline c & zie voor betekenis Protocol 1.1 & 33 & 70 & 70 & 33 & 90 & 33 & 70 & 33 & 70 & 70 \\
\hline D & zie voor betekenis Protocol 1.1 & 70 & 50 & 50 & 70 & 50 & 70 & 50 & 70 & 50 & 50 \\
\hline E & zie voor betekenis Protocol 1.1 & 0 & 0 & 0 & 0 & 0 & 0 & 0 & 0 & 0 & 0 \\
\hline $\mathrm{F}$ & zie voor betekenis Protocol 1.1 & 100 & 100 & 100 & 100 & 100 & 100 & 100 & 100 & 100 & 100 \\
\hline G & zie voor betekenis Protocol 1.1 & 73 & 55 & 24 & 57 & 12 & 80 & 65 & 56 & 29 & 69 \\
\hline $\mathrm{H}$ & zie voor betekenis Protocol 1.1 & 85 & 73 & 54 & 73 & 53 & 88 & 79 & 72 & 56 & 81 \\
\hline 1 & zie voor betekenis Protocol 1.1 & 1.0 & 1.0 & 3.1 & 7.3 & 2.0 & 1.3 & 1.2 & 6.4 & 4.8 & 1.3 \\
\hline j & zie voor betekenis Protocol 1.1 & 9.6 & 7.8 & 12.9 & 13.5 & 4.6 & 7.2 & 6.0 & 14.3 & 11.7 & 5.3 \\
\hline $\mathrm{k}$ & zie voor betekenis Protocol 1.1 & 14.4 & 26.0 & 43.0 & 20.1 & 45.5 & 10.8 & 20.0 & 21.3 & 39.0 & 17.5 \\
\hline ¿ & zie voor betekenis Protocol 1.1 & 0.0 & 0.0 & 0.0 & 0.0 & 0.0 & 0.0 & 0.0 & 0.0 & 0.0 & 0.0 \\
\hline M & zie voor betekenis Protocol 1.1 & 0.0 & 0.0 & 0.0 & 0.0 & 0.0 & 0.0 & 0.0 & 0.0 & 0.0 & 0.0 \\
\hline \multirow[t]{3}{*}{$\mathrm{N}$} & zie voor betekenis Protocol 1.1 & 15.8 & 36.4 & 60.2 & 22.1 & 81.9 & 11.9 & 28.0 & 23.4 & 54.6 & 24.5 \\
\hline & CHECK eerste jaar & 100 & 100 & 100 & 100 & 100 & 100 & 100 & 100 & 100 & 100 \\
\hline & CHECK langere termijn & 100 & 100 & 100 & 100 & 100 & 100 & 100 & 100 & 100 & 100 \\
\hline
\end{tabular}

Factor A te meten, of als verstekwaarde overnemen uit http://www.bemestingsadvies.nl

Factor B: ammoniak-emissiefactoren (naar Van Bruggen et al., 2017)

\begin{tabular}{|c|c|c|c|c|}
\hline Grondgebruik & Methode & $\begin{array}{l}\text { vaste mest, } \\
\text { dikke fractie }\end{array}$ & drijfmest & $\begin{array}{l}\text { gier, dunne fractie, } \\
\text { spuiwater }\end{array}$ \\
\hline \multirow[t]{4}{*}{ grasland } & bovengronds & 74 & 74 & 74 \\
\hline & sleepvoet & - & 26 & 10 \\
\hline & sleufkouter & - & 23 & 10 \\
\hline & zodenbemester & - & 19 & 8 \\
\hline \multirow[t]{5}{*}{ bouwland } & bovengronds & - & 69 & 69 \\
\hline & in twee werkgangen onderwerken & 46 & - & - \\
\hline & in één werkgang onderwerken & - & 22 & 22 \\
\hline & sleepvoet & - & 36 & 12 \\
\hline & injectie & - & 2 & 2 \\
\hline
\end{tabular}

40 | Rapport WPR-916 



stof/Kengetallen-organische-stof.htm)

\begin{tabular}{ll} 
Mestsoort & HC $(\%)$ \\
GFT en groencompost & 90 \\
\hline rundveemest & 70 \\
\hline schapen, geiten & 70 \\
\hline champost & 50 \\
\hline varkens- en kippenmest & 33 \\
\hline graanstro & 30 \\
\hline groen plantmateriaal & 25
\end{tabular}


Gewas Tijdigheid (\%)

\begin{tabular}{ll} 
grasland zonder vochtgebrek & 90 \\
\hline grasland met nazomer vochtgebrek & 75 \\
\hline granen & 50 \\
\hline maïs & 60 \\
\hline bieten & 70
\end{tabular}


Factor $\mathrm{E}$ : extra denitrificatie bij gebruik van organische bemesting (inschatting)

\begin{tabular}{|c|c|c|c|c|}
\hline Vergisting & Mestsoort & Grondsoort & Positionering & Denitrificatie ( $\%$ van toegediende $\mathrm{N}$-totaal na aftrek van ammoniak- $\mathrm{N}$ verliezen \\
\hline \multirow[t]{8}{*}{ nee } & meermagig & zand & ondiep & 0 \\
\hline & & & diep & 0 \\
\hline & & klei & ondiep & 0 \\
\hline & & & diep & 5 \\
\hline & eenmagig & zand & ondiep & 0 \\
\hline & & & diep & 5 \\
\hline & & klei & ondiep & 10 \\
\hline & & & diep & 15 \\
\hline \multirow[t]{8}{*}{ ja } & meermagig & zand & ondiep & 0 \\
\hline & & & diep & 0 \\
\hline & & klei & ondiep & 0 \\
\hline & & & diep & 0 \\
\hline & eenmagig & zand & ondiep & 0 \\
\hline & & & diep & 0 \\
\hline & & klei & ondiep & 5 \\
\hline & & & diep & 10 \\
\hline
\end{tabular}

Factor F: relatieve efficiëntie (\%) van mest-N die in eerste jaar plantbeschikbaar is of komt Wijze van toediening Efficiëntie

Weidemest

rijenbemesting
25

125 (expert judgement Werkgroep Onderbouwing Derogatie)

Schröder et., 2015) 
Protocol 1.9 Rekenregels gebruikt bij berekening van Protocol 1.1

\begin{tabular}{cl}
\hline Factor & Rekenregel \\
\hline$G$ & $\mathrm{Fx}((\mathrm{A} \times(100-\mathrm{B}) / 100 \times(100-\mathrm{E}) / 100+(100-\mathrm{A}) \times(100-\mathrm{C}) / 100 \times \mathrm{D} / 100) \times(100-\mathrm{E}) / 100)$ \\
$\mathrm{H}$ & $\mathrm{Fx}((\mathrm{A} \times(100-\mathrm{B}) / 100 \times(100-\mathrm{E}) / 100+(100-\mathrm{A}) \times(100-\mathrm{C}) / 100 \times \mathrm{D} / 100) \times(100-\mathrm{E}) / 100)+(100-\mathrm{A}) \times \mathrm{C} / 100 \times \mathrm{D} / 100 \times(100-\mathrm{E}) / 100$ \\
$\mathrm{I}$ & $\mathrm{A} \times \mathrm{B} / 100$ \\
$\mathrm{~J}$ & $(100-\mathrm{A})^{*}(100-\mathrm{C}) / 100^{*}(100-\mathrm{D}) / 100$ \\
$\mathrm{~K}$ & $(100-\mathrm{A})^{*}(100-\mathrm{C}) / 100^{*}(100-\mathrm{D}) / 100+(100-\mathrm{A})^{*}(\mathrm{C} / 100)^{*}(100-\mathrm{D}) / 100$ \\
$\mathrm{~L}$ & $\mathrm{~A}^{*}(100-\mathrm{B}) / 100^{*}\left((100-\mathrm{F}) / 100+\mathrm{F} / 100^{*} \mathrm{E} / 100\right)+(100-\mathrm{A})^{*}(100-\mathrm{C}) / 100^{*} \mathrm{D} / 100^{*}\left((100-\mathrm{F}) / 100+\mathrm{F} / 100^{*} \mathrm{E} / 100\right)$ \\
$\mathrm{M}$ & $\mathrm{A}^{*}(100-\mathrm{B}) / 100^{*}\left((100-\mathrm{F}) / 100+\mathrm{F} / 100^{*} \mathrm{E} / 100\right)+(100-\mathrm{A})^{*}(100-\mathrm{C}) / 100^{*} \mathrm{D} / 100^{*}\left((100-\mathrm{F}) / 100+\mathrm{F} / 100^{*} \mathrm{E} / 100\right)+(100-\mathrm{A})^{*}(\mathrm{C}) / 100^{*} \mathrm{D} / 100^{*} \mathrm{E} / 100$ \\
$\mathrm{~N}$ & $(100-\mathrm{A}) \times \mathrm{C} / 100$ \\
&
\end{tabular}




\section{Bijlage 2 Verloop van wettelijke NWC's van varkensdrijfmest en enkele $\mathrm{N}$-gebruiksnormen}

\begin{tabular}{|c|c|c|c|c|c|c|c|c|c|c|}
\hline \multirow{3}{*}{$\begin{array}{l}\text { Actie- } \\
\text { programma }\end{array}$} & \multirow[t]{3}{*}{ Jaar } & \multicolumn{3}{|c|}{ NWC van varkensdrijfmest op (\%) } & \multicolumn{6}{|c|}{ N-gebruiksnorm (kg/ha) bij: } \\
\hline & & \multirow[b]{2}{*}{ Klei } & \multirow[b]{2}{*}{ Zand \& Löss } & \multirow[b]{2}{*}{$\begin{array}{l}\text { Zand \& Löss in Noord- } \\
\text { Brabant en Limburg }\end{array}$} & \multicolumn{3}{|c|}{ Consumptieaardappel } & \multicolumn{3}{|c|}{ Snijmaïs** } \\
\hline & & & & & Klei & Zand \& Löss & $\begin{array}{l}\text { Zand \& Löss in Noord- } \\
\text { Brabant en Limburg }\end{array}$ & Klei & Zand \& Löss & $\begin{array}{l}\text { Zand \& Löss in Noord- } \\
\text { Brabant en Limburg }\end{array}$ \\
\hline \multirow[t]{2}{*}{$3 e$} & $2006-2008$ & 60 & 60 & & 275 & 265 & & $205(160)$ & $185(155)$ & \\
\hline & 2009 & 60 & 60 & & 250 & 245 & & $185(160)$ & $150(150)$ & \\
\hline \multirow[t]{4}{*}{$4 e$} & 2010 & 60 & 65 & & 250 & 245 & & $185(160)$ & $150(150)$ & \\
\hline & 2011 & 60 & 70 & & 250 & 245 & & $185(160)$ & $150(150)$ & \\
\hline & 2012 & 60 & 70 & & 250 & 235 & & $185(160)$ & $150(150)$ & \\
\hline & 2013 & 60 & 70 & & 250 & 235 & & $185(160)$ & $150(150)$ & \\
\hline \multirow[t]{2}{*}{$5 e$} & 2014 & 60 & 80 & & 250 & 235 & & $185(160)$ & $140(140)$ & \\
\hline & 2015-2017 & 60 & 80 & $85^{* * *}$ & 250 & 235 & 188 & $185(160)$ & $140(140)$ & $112(112)$ \\
\hline $6 e$ & $2018-2021$ & 60 & 80 & $85^{* * *}$ & 250 & 235 & 188 & $185(160)$ & $140(140)$ & $112(112)$ \\
\hline
\end{tabular}

*voor de zogenaamde 'overige' rassen

** tussen haken voor bedrijven mét derogatie

***wel in Nederlandse Actieprogramma Nitraatrichtlijn, maar niet geëffectueerd in wetgeving (bron: https://www.rvo.nl/sites/default/files/2019/01/Tabel-3-Werkingscoefficient-2019-2021.pdf) 


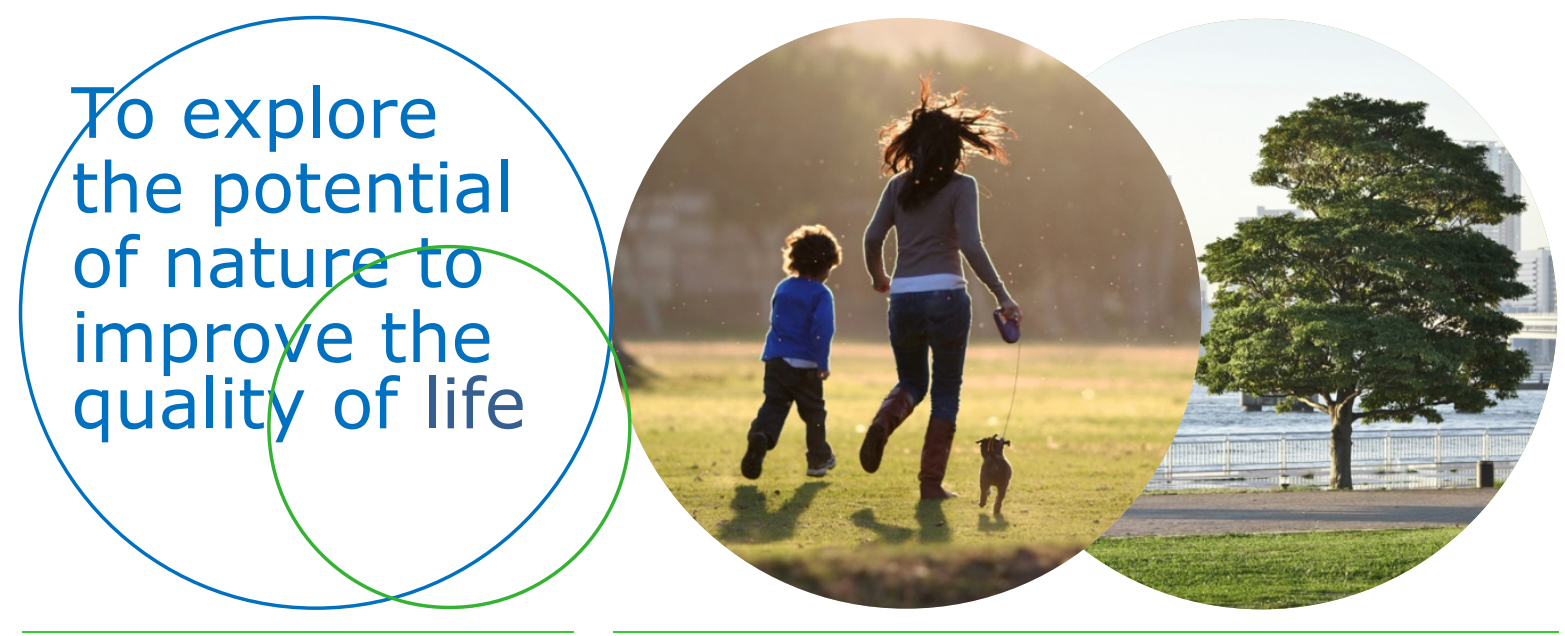

Correspondentie adres voor dit rapport: Postbus 16

6700 AA Wageningen

T 0317480700

www.wur.nl/plant-research

Rapport WPR-916
De missie van Wageningen University \& Research is 'To explore the potential of nature to improve the quality of life'. Binnen Wageningen University \& Research bundelen Wageningen University en gespecialiseerde onderzoeksinstituten van Stichting Wageningen Research hun krachten om bij te dragen aan de oplossing van belangrijke vragen in het domein van gezonde voeding en leefomgeving. Met ongeveer 30 vestigingen, 5.000 medewerkers en 10.000 studenten behoort Wageningen University \& Research wereldwijd tot de aansprekende kennisinstellingen binnen haar domein. De integrale benadering van de vraagstukken en de samenwerking tussen verschillende disciplines vormen het hart van de unieke Wageningen aanpak.



